ECCOMAS

Proceedia
COMPDYN 2021

$8^{\text {th }}$ ECCOMAS Thematic Conference on Computational Methods in Structural Dynamics and Earthquake Engineering M. Papadrakakis, M. Fragiadakis (eds.)

\title{
INFLUENCE OF STRUCTURAL INELASTIC BEHAVIOR IN THE STUDY OF COLLIDING SDOF STRUCTURES
}

\author{
Folhento P. Pedro ${ }^{1}$, Barros C. Rui ${ }^{1}$, and Braz-César T. Manuel $^{2}$ \\ ${ }^{1}$ CONSTRUCT, Faculdade de Engenharia, Universidade do Porto \\ FEUP, Porto, Portugal \\ \{up201811645, rcb\}@fe.up.pt \\ ${ }^{2}$ CONSTRUCT, Politécnico Instituto de Bragança \\ IPB, Bragança, Portugal \\ brazcesar@ipb.pt
}

\begin{abstract}
Earthquake-induced structural pounding between buildings is an insurgent field of investigation since in metropolitan areas it is very common to construct buildings very close to each other leaving small gap distances in between or even no space at all, increasing the likelihood of structural collisions in an earthquake event. These impacts can provoke substantial structural damage or global collapse of building structures. The overall dynamic behavior is thus greatly affected by this phenomenon and so importance should be given in the study of the respective consequences. The most practical and simple approach is to model buildings as SDOF lumped mass models considering elastic behavior. However, it has been verified previously that neglecting inelastic behavior in these situations can lead to significant overestimations of the magnitude and number of impacts between the adjacent structures and underestimations of the displacement responses, especially in flexible structures. In this sense, the influence of inelastic behavior in SDOF structural systems is carried out using a smooth hysteresis model, implemented in a Matlab-Simulink model, for different levels of hysteresis degradation phenomena under cyclic loading. This parametric study will enable a further understanding of the inelastic behavior of structures under pounding forces.
\end{abstract}

Keywords: Building structural pounding, Earthquake-induced pounding, Impact modeling, Inelastic behavior, Parametric study. 


\section{INTRODUCTION}

Non-linear inelastic behavior and significant damage are usually observed in building structures when subjected to earthquake events.

Loss of human lives, total or partial destruction of built patrimony, and human activity are consequences that seismic design seeks to avoid and in the case of significant structural damage to limit it to permit for possible repair and/or substitution of damaged elements in the structures.

Seismic design of building structures can be performed using linear or non-linear, static or dynamic analysis. When inelastic behavior is considered it is usually assumed to be lumped at beam's ends, critical regions, commonly called plastic hinges that require an adequate structural detail to possess acceptable ductility, while other zones should be kept in the elastic range with overstrength, forming the strong links in the structural system, the case of columns and the middle span of beams. Nevertheless, the behavior of columns should be assessed since, in reality, these elements will suffer some inelastic deformation (due to redistribution of forces within the structure) that should be evaluated by analyzing its lateral restoring forces.

To reproduce this inelastic behavior, the common assumption is to consider for plastic hinges known constitutive behavior translated by a suitable hysteresis model capable of emulating different physical phenomena such as stiffness degradation, strength deterioration, and the pinching effect.

Hence, it is well known and expected that permanent damage will occur under moderate to severe earthquakes. One phenomenon that has been progressively studied over recent years is structural pounding between buildings that have very limited separation distance or no distance at all. Earthquake-induced structural pounding between buildings has revealed significant negative effects that may lead to the global collapse of the structural systems. Large ductility and energy dissipation demands are verified in buildings under earthquake-induced pounding.

To emulate structural building pounding several approaches have been developed and are present in the literature. The simplest approach is the consideration of impact models based on some simplifications and assumptions that capture the essence of the impacts, i.e., its magnitude. This phenomenon is extremely or virtually impossible to emulate with perfect accuracy, being associated with non-linear relationships between the contact area, stresses, and deformations; local inelastic deformations; propagation of stress waves in the involved structures; friction forces; vibrations resulting in thermal and acoustic effects; etc.

Due to these short-duration impulses, i.e., huge forces involving large masses in an incredibly short amount of time, it is known to cause inevitable local and global structural damage and thus, influencing the overall dynamic responses of the colliding buildings.

Thus, this paper intends to analyze how different kinds of hysteresis behaviors may influence the pounding-involved response of buildings under seismic events.

To achieve this the usual approach of assuming two single-degree-of-freedom (SDOF) lumped mass models with very different dynamic behavior is considered. These structural systems are connected by a zero-length element, an impact model.

A smooth hysteresis model is implemented to emulate the non-linear inelastic behavior of the structures.

The elastic case and the inelastic behavior with different levels/cases of hysteresis degradation phenomena under cyclic loading and structural pounding are then simulated using a developed Matlab-Simulink model. The results are then presented in terms of graphs and peak responses to enable a further understanding of the inelastic behavior of building structures under earthquake-induced pounding forces. 


\section{HYSTERESIS BEHAVIOR CASES}

The relationship between the input and the output in the inelastic range is controlled by the rate-independent memory effect concept, that is, a hysteresis operator, that takes in an input function and returns an output function. This phenomenological concept is based on experimental data relating the input-output pair.

The response of structural systems depends always on the rate of the applied load when this needs to be considered viscosity is introduced along with the rate-independent restoring force. Hence, the usual dynamic equation of motion is modified, including the lateral restoring force (in this study) term, $f_{r}^{*}$, that depends on the displacements and velocities of the system, to become

$$
m \ddot{x}(t)+c \dot{x}(t)+k x(t)=-m \ddot{x}_{g}(t) \Leftrightarrow m \ddot{x}(t)+c \dot{x}(t)+a k_{0} x(t)+f_{r}^{*}(t)=-m \ddot{x}_{g}(t)
$$

where $m, k$, and $c$ are, respectively, the mass, the elastic stiffness and the viscous damping of the structure, $\ddot{x}_{\mathrm{g}}(t)$ is the earthquake's acceleration, $x(t)$ is the structural displacement, $\dot{x}$ is the structural velocity, and $\ddot{x}(t)$ is the structure's acceleration.

To account for the inelastic behavior several empirical hysteresis models were developed by many researchers and can be broadly categorized into polygonal and smooth hysteresis models. In the present study, a smooth hysteresis model is considered. This model was developed by Sivaselvan and Reinhorn [1] and is a subsequent modification of the original BoucWen model ([2]-[4]).

A schematic representation of the abovementioned hysteresis model is presented in Figure 1 which is capable of simulating different behaviors of a structural system under cyclic loading, viz., strength hardening, the Bauschinger effect, stiffness degradation, strength deterioration, and the pinching effect.

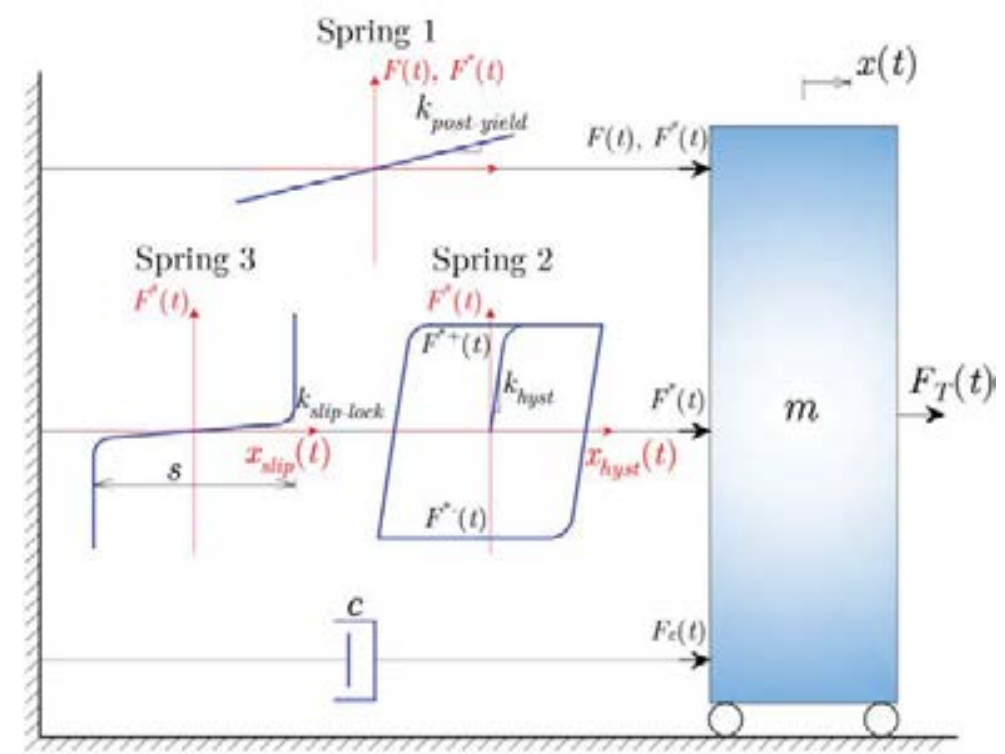

Figure 1: Sivaselvan and Reinhorn's smooth hysteresis model schematic representation.

The following subsections describe the model in [1] and present different hysteresis behavior cases that can be considered depending on the type of structural system and material used for simulation. Three springs define the model and the different hysteresis cases: a post-yield spring (Spring 1), a hysteresis spring (Spring 2), and a slip-lock spring (Spring 3) as can be observed in Figure 1. 


\subsection{Plain hysteresis}

Plain hysteresis behavior is characterized by a case of hysteresis that can account for strength hardening and possess no degradation features. In the present investigation, this will be denominated by Case 0 of hysteresis behavior. This behavior is suitable for well-detailed steel structures, e.g., special moment resisting frames (SMRFs) [5].

Upon the application of a load, the springs 1 and 2 in parallel undergo the same deformation, although they share this force in proportion to their instantaneous stiffness,

$$
k=k_{\text {post-yield }}+k_{\text {hyst }}
$$

in which the post-yielding stiffness, $k_{\text {post-yield, }}$ is represented by a linear elastic spring (Spring 1), and the hysteresis spring, khyst, is represented by a pure elasto-plastic spring with a smooth transition from the elastic to the inelastic range (Spring 2).

The previous stiffnesses terms, the elastic stiffness, and the non-degrading hysteresis stiffness are given, respectively, by the following expressions

$$
\begin{gathered}
k_{\text {post-yield }}=a k_{0} \\
k_{\text {hyst }}=(1-a) k_{0}\left\{1-\left|\frac{F^{*}}{F_{Y}^{*}}\right|^{n_{W}}\left[\eta_{1} \operatorname{sgn}\left(F^{*} d x\right)+\eta_{2}\right]\right\}
\end{gathered}
$$

in which $a$ is the post to pre-yielding stiffness ratio, $n_{W}$ controls the smoothness of the transition from elastic to plastic stages, $\eta_{1}$ and $\eta_{2}$ are parameters that control the shape of the unloading curve, $F^{*}$ and $F_{Y}{ }^{*}$ are the portion of the applied force shared by the hysteresis spring and its respective yield value.

\subsection{Stiffness degradation}

Stiffness degradation is considered by the introduction of an additional parameter, $R_{K}$, a positive parameter with the unity as its possible maximum value. This factor is given by the following expression

$$
R_{K}=\frac{F^{*}+\alpha F_{Y}^{*}}{k_{0} x+\alpha F_{Y}^{*}}
$$

The stiffness degradation is implemented in the Matlab-Simulink model through the socalled pivot rule [6]. This degradation phenomenon is observed in several structural elements and systems under cyclic loading and occurs due to non-linear geometric effects [7] and the elastic stiffness degrades with increasing ductility [1]. The degree of stiffness decay depends on the characteristics of the structure, e.g., material properties, geometry, ductility capacity, and connection type; and on the loading history, e.g., the intensity in each cycle, number of cycles, and sequence of loading cycles [8].

In the case of reinforced concrete (RC) components under severe cyclic loading, this degradation can be the result of cracking, loss of bond, or interaction with high shear or axial stresses [8]. Reduced stiffness in steel elements can be attributed to the Bauschinger effect [9] and is caused by accumulated damage or fatigue.

This type of hysteresis behavior in this study will be designated as Case 1. Hence, the hysteresis stiffness in Equation 4 is modified by including parameter $R_{K}$ in Equation 5 which depends on parameter $\alpha$ (measuring the degree of stiffness degradation), as follows 


$$
k_{\text {hyst }}=\left(R_{K}-a\right) k_{0}\left\{1-\left|\frac{F^{*}}{F_{Y}^{*}}\right|^{n_{W}}\left[\eta_{1} \operatorname{sgn}\left(F^{*} d x\right)+\eta_{2}\right]\right\}
$$

\subsection{Strength deterioration}

Two main types of strength deterioration can be identified: cyclic strength degradation and in-cycle strength degradation [8]. Cyclic strength degradation refers to the loss of strength and stiffness in subsequent cycles. As for the in-cyclic strength, degradation is characterized by a reduction of strength during the current cycle, leading to a negative stiffness. This type of behavior occurs when a structural component subjected to increasing deformation reaches the capacity boundary. Since a cyclic load-path cannot pass through this limit, the response continues along the boundary until unloading occurs, producing the in-cycle strength degradation.

According to FEMA's report [8], cyclic reduction of lateral strength is based on the increasing inelastic displacement and ultimately on the peak displacement, and on the total hysteresis energy demands of the system translated by the area enclosed by the hysteresis cycles. On the other hand, in-cyclic strength degradation along with stiffness degradation may occur due to geometric (P-delta effects) and/or material non-linearities. Material nonlinearities that may cause in-cycle strength degradation include concrete crushing, shear failure, buckling or fracture of longitudinal reinforcement, and splice failures for RC components; and for steel components include buckling of bracing elements, local buckling in flanges of columns or beams, and fracture of bolts, or welds. The first type of deterioration usually specifies this decay in terms of the ductility ratio, and the second is the result of a single level of inelastic displacement imposed many times (along with the cycles), reducing the lateral strength level as the number of cycles increases.

The authors [1] considered in the current model a deterioration rule that reduces the capacity of the backbone curve. This rule of deterioration is based on a continuous energy-based degradation, and on a backbone degradation which occurs when the maximum deformation value attained in the past is exceeded and is given by the following expression

$$
F_{Y}^{+/-}=F_{Y 0}^{+/-}\left[1-\left(\frac{x_{\max }^{+/-}}{x_{\text {ult }}^{+/-}}\right)^{\frac{1}{\beta_{1}}}\right]\left[1-\frac{\beta_{2}}{1-\beta_{2}} \frac{E_{h}}{E_{\text {hult }}}\right]
$$

where $F_{Y}^{+--}$is the positive or negative yield force, $F_{Y 0}{ }^{+/-}$is the initial positive or negative yield force, $x_{\max }{ }^{+-}$is the maximum positive or negative displacement, $x_{\mathrm{ult}}{ }^{+/-}$is the ultimate positive or negative displacement, $E_{h}$ is the hysteresis energy dissipated, $E_{h u l t}$ is the hysteresis energy dissipated when loaded monotonically until the ultimate displacement without any degradation, $\beta_{1}$ is a parameter based on ductility demands, and $\beta_{2}$ is a parameter based on energy demands. The second term on the right side of Equation 7 is related to strength deterioration based on increased deformation and the last term is related to the hysteresis energy dissipated.

Stiffness and strength degradation will be considered together as Case 2 of hysteresis behavior for the present investigation.

\subsection{Pinching effect}

The pinching effect is another phenomenon observed in structural components and connections subjected to cyclic lateral load. The name pinching arises from the effect that has on the hysteresis loops. Pinched or compressed hysteresis cycles are obtained by great reductions in stiffness during reloading and stiffness recovery when the opposite displacement is imposed. 
This phenomenon is mostly observed in brittle materials, viz., RC elements, timber components, and some types of masonry components. Some connections in steel structures also exhibit this kind of effect. In RC elements, pinching is the consequence of cracks that open when the element deforms in a certain direction. On load reversal, the deformation in the opposite direction closes the cracks and the stiffness is partially recovered. In timber structures, the main cause of pinching is the opening and closing of gaps in bordering elements due to nail pullout. Reinforced masonry also experiences pinching due to the opening and closing of flexural cracks, gaps between the masonry infill and the bordering structural frame, and between plates in steel-end connections [8]. In addition, the degree of pinching essential depends on the material properties, geometry, ductility, and connections of the structure, as well as the loading history, in terms of the intensity and sequence of the loading cycles.

An additional spring (Spring 3) is thus implemented in the hysteresis model to simulate pinching behavior [1]. A "slip-lock" spring is added in series to the hysteresis spring as illustrated in Figure 1. The combined stiffness now becomes

$$
k=k_{\text {post-yield }}+\frac{k_{\text {hyst }} k_{\text {slip-lock }}}{k_{\text {hyst }}+k_{\text {slip-lock }}} \text { where } \quad k_{\text {slip-lock }}=\left\{\sqrt{\frac{2}{\pi}} \frac{s}{F_{\sigma}^{*}} \exp \left[-\frac{1}{2}\left(\frac{F^{*}-F_{m}^{*}}{F_{\sigma}^{*}}\right)^{2}\right]\right\}^{-1}
$$

in which $s$ is the slip length, $F_{\sigma}{ }^{*}$ is a measure of the force range over which slip occurs, and $F_{m}{ }^{*}$ is the mean force level on either side about which slip occurs, being these three parameters given, respectively, as follows

$$
\begin{gathered}
s=R_{s}\left(x_{\max }^{+}-x_{\max }^{-}\right) \\
F_{\sigma}^{*}=\sigma F_{Y}^{*} \\
F_{m}^{*}=\lambda_{s} F_{Y}^{*}
\end{gathered}
$$

where parameters $R_{s}, \sigma_{s}$, and $\lambda_{s}$ are parameters that control each of the resulting values of the previous three equations.

Proper calibration of these hysteresis parameters presented in the present section (in Equations 2-11) can model different hysteresis behaviors depending on material properties and structural systems.

This hysteretic model will be further implemented in this investigation to assess the inelastic behavior of the structures under the earthquake-induced pounding.

Stiffness and strength degradation with the pinching effect will be denoted as Case 3 of hysteresis behavior in the following sections.

\section{STRUCTURAL POUNDING MODELING}

Structural pounding involves complex phenomena making the problem of earthquakeinduced structural building pounding extremely difficult to model with high accuracy. However, in structural pounding, the estimation of the magnitude of pounding forces with satisfactory accuracy is enough to verify its influence on the overall dynamic response of the colliding structures.

Two possible ways of earthquake-induced structural pounding modeling are available in the literature: the classical theory of impact and the use of impact or contact elements [10].

The classical theory of impact fails to describe transient stresses and to account for local deformations at the contact point of the bodies assuming that a negligibly part of the initial kinetic energy of the system is transformed into vibrations of the colliding bodies [11]. Addi- 
tionally, it does not consider the existence of the period of impact failing to directly assess the evolution of the pounding forces during collision [12].

The coefficient of restitution (CR) is a parameter derived in the first approach of pounding modeling. This parameter depends on the relative final $\left(\dot{x}_{2, f}-\dot{x}_{1, f}\right)$ and initial $\left(\dot{x}_{2,0}-\dot{x}_{1,0}\right)$ impact velocities and represents the energy losses and degree of plasticity of the impact being directly related with the kinetic energy loss during impact. CR is given by the following expression

$$
\mathrm{CR}=\frac{\dot{x}_{2, f}-\dot{x}_{1, f}}{\dot{x}_{1,0}-\dot{x}_{2,0}}
$$

Impact models constitute the second approach to model building pounding, largely used in many investigations to assess the detrimental effects of impacts in building structures. From the consideration of two periods of impact, approach and restitution periods, to the penalty method and establishment of parameters such as impact stiffness and impact damping ratio, the impact models have been widely used providing relative satisfactory accuracy in replicating the pounding forces arising from the contact of buildings during earthquake events. Although, the formulation of these elements is based on Hertz's theory and oversimplified assumptions making the problem simpler yet less accurate.

Among these simplifications, one can mention [13]: the stress wave propagation is neglected and the state of stress in the structures at any instant can be considered approximately uniform. This ignores the dynamic effects in the structures due to wave propagation, assuming that structural pounding between buildings can be approximately quasi-static if the duration of the impact is long enough to allow stress waves to transverse the length of the body many times, justifying in this way the use of spring-dashpot elements; the contact area is in general elliptical and is assumed to be small in comparison with the principal dimensions of the bodies; deformations are restricted to the vicinity of the impact; contact surfaces are nonconforming, smooth, continuous and frictionless; and the contact regions are assumed to remain elastic and unaltered after impact events.

In these compression-only impact models with zero-length, the spring will control the restoring force and deformation, and the dashpot will account for the energy radiated due to impact by wave motion. Hence, these two elements in the model represent the impact stiffness $\left(k_{i m p}\right)$ which depends on material properties and the contact geometry, and the impact damping ratio $\left(\xi_{\text {imp }}\right)$ that depends mostly on the CR being derived from energy considerations.

Different impact models have been developed. The simplest model is the consideration of a spring, hence possessing only the elastic part of the impact correspondent to the impact spring and lacking the ability to account for energy dissipation during a collision. Similarly, the nonlinear elastic model following Hertz's contact law [14], describes the static compression between two isotropic elastic bodies and is also limited by the lack of energy dissipation during impact. The spring non-linearity is capable of modeling the force-deformation relation more realistically. The impact force increases with the interpenetration depth to the power of 1.5

$$
f_{P}(t)= \begin{cases}\beta_{\text {imp }}[\delta(t)]^{\frac{3}{2}} & \text { for } \delta(t)>0 \\ 0 & \text { for } \delta(t) \leq 0\end{cases}
$$

in which $\beta_{\text {imp }}$ is a parameter indicating the non-linear impact stiffness depending on material properties and geometry of the colliding structures. 
The two impact models mentioned in the previous paragraph were the target of many modifications through the years, mostly to correct its drawbacks and increase the accuracy in modeling pounding forces.

A central modification to the linear elastic model was carried out giving rise to the linear viscoelastic or Kelvin-Voigt impact model [15], having now the ability to account for the loss of energy during impact. Pounding forces are thus computed using the following expressions

$$
f_{P}(t)= \begin{cases}k_{i m p} \delta(t)+c_{i m p} \dot{\delta}(t), & \text { for } \delta(t)>0 \\ 0 & \text { for } \delta(t) \leq 0\end{cases}
$$

where $c_{\text {imp }}$ is the damping constant of the pounding contact element computed by the following expression ([16], [17])

$$
c_{i m p}=2 \xi_{i m p} \sqrt{k_{i m p} \frac{m_{1} m_{2}}{m_{1}+m_{2}}} \text { where } \xi_{\text {imp }}=\frac{-\ln (\mathrm{CR})}{\sqrt{\pi^{2}+[\ln (\mathrm{CR})]^{2}}}
$$

However, this modification revealed a tensile force at the end of the impact period due to the uniform dissipation of energy on both periods of impact, which in reality does not happen ([10], [11]). This model further suffered different modifications to address this drawback. Komodromos et al. [18] modified the linear viscoelastic model by eliminating the negative force making it zero. Valles and Reinhorn [19], modified the Kelvin-Voigt model by assuming that the damping term is activated only for positive velocities during impact, which means only activated during the approach period. Mahmoud [20] addressed the drawbacks of the linear viscoelastic impact model with the same line of reasoning in [19] but redefining the expression of the impact damping ratio through energy considerations. Ye et al. [21] and Pant et al. ([22], [23]) proposed different modifications providing a different expression for the impact damping ratio. Following the research in [20], Mahmoud and Jankowski [24] suggested a further modification to the linear viscoelastic model using a different approach to arrive at an improved formula for the impact damping ratio.

Hertz's model (Equation 13) was modified by Lankarani and Nikraves ([25], [26]), to address the matter of the lack of energy dissipation properties by including in parallel with the non-linear spring a non-linear damping proposed by Hunt and Crossley [27] to better represent impacts between mechanical systems. Similar to the previous modifications, this model now becomes a non-linear viscoelastic impact model. Muthukumar and DesRoches ([28], [29]) considered the previous model applied to civil engineering structures being designated by the "Hertzdamp" impact model. An important modification to the Hertzdamp model was carried out by Jankowski [30] suggesting that the non-linear damping component becomes active only in the approach period where most energy is dissipated. Figure 2 presents a representation of Jankowski's non-linear viscoelastic model.

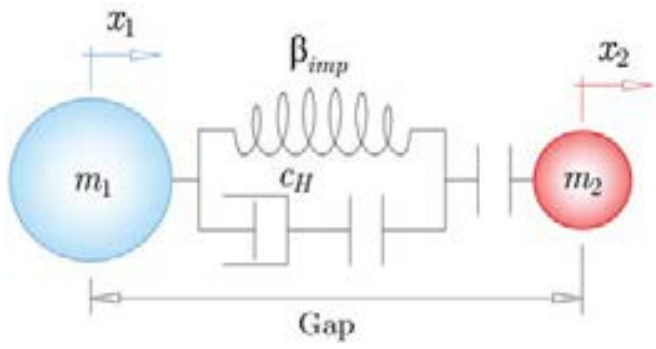

Figure 2: Schematic representation of Jankowski’s non-linear viscoelastic model.

The pounding force can thus be calculated using the following system of equations [30] 


$$
f_{P}(t)= \begin{cases}\beta_{\text {imp }}[\delta(t)]^{\frac{3}{2}}+c_{H}(t) \dot{\delta}(t) & \text { for } \delta(t)>0 \text { and } \dot{\delta}(t)>0 \\ \beta_{\text {imp }}[\delta(t)]^{\frac{3}{2}} & \text { for } \delta(t)>0 \text { and } \dot{\delta}(t) \leq 0 \\ 0 & \text { for } \delta(t) \leq 0\end{cases}
$$

where the damping coefficient is determined as follows

$$
c_{H}(t)=2 \xi_{i m p} \sqrt{k_{i m p} \frac{m_{1} m_{2}}{m_{1}+m_{2}}} \text { where } \quad k_{i m p}=\beta_{\text {imp }} \sqrt{\delta(t)}
$$

and the impact damping ratio, which had to be redefined was approached by using two different approximating functions in the process, leading to two expressions from which one was found more accurate and is thus shown below [31]

$$
\xi_{i m p}=\frac{9 \sqrt{5}}{2} \frac{1-\mathrm{CR}^{2}}{\mathrm{CR}[\mathrm{CR}(9 \pi-16)+16]}
$$

Further modifications were carried out to the Hertzdamp impact model. Ye et al. [32] based on the resulting relationship between the CR and the impact damping ratio developed a new and more rational expression for the damping ratio.

More recent modifications to the core impact models presented in previous paragraphs were carried out, mostly modifications to the relation between the impact damping ratio and the CR, e.g., Naderpour et al. ([33], [34]) and Khatami et al. [35].

A different modification was carried out by Bamer et al. ([36]-[38]) to include damage provoked by repetitive impacts which are known to happen in inelastic impacts translated implicitly by parameter CR. This was made by the inclusion of a dry friction element in series with the non-linear spring from the Hertzdamp model or the Jankowski's non-linear viscoelastic model (respectively, [36] and [37]).

Hence, most of the investigations concerning the development of impact models are based on the correct establishment or calibration of the impact stiffness and impact damping ratio. These parameters along with the coefficient of restitution, are the core of the impact models and their accuracy depends on how accurate is the estimation of these parameters. Unfortunately, these parameters are also subjected to great sources of uncertainties, viz., the geometry of the region of impact, material properties, impact velocities, stiffness and mass properties of the involved buildings, etc. These uncertainties may be addressed by performing validation experimental tests and performing parametric sensitivity analysis, which allows for additional information reducing the epistemic error in the models and understanding which parameters are important and relevant to consider and the ones that have no or little influence in the model. Some experimental tests regarding impacts and the calibration of the abovementioned parameters have been carried out ([39]-[43]).

It should be referred that the previous models mostly addressed central impact, i.e., impacts in one direction and a predefined location and geometry of impact. In reality, buildings will have correlated translational and rotational responses which makes the location and geometry of impacts unknown being a more complex model to study. In addition, the neglection of tangential forces and friction constitutes one of the assumptions of the previous models that may have a substantial effect on the overall dynamic response of building structures under earthquake-induced pounding. The work of Polycarpou et al. [44] addressed these situations by using a rational three-dimensional spatial model supported by previous considerations of impact models and by classical theory of contact mechanics considerations. 


\section{NUMERICAL MODELING PROCEDURE}

The numerical models consist of two SDOF systems that can have elastic or inelastic behavior. The inelastic behavior will be considered by four representative cases of frame behavior. The two SDOF systems will represent two buildings with very different dynamic properties and are assumed as lumped mass models as sketched in Figure 3.

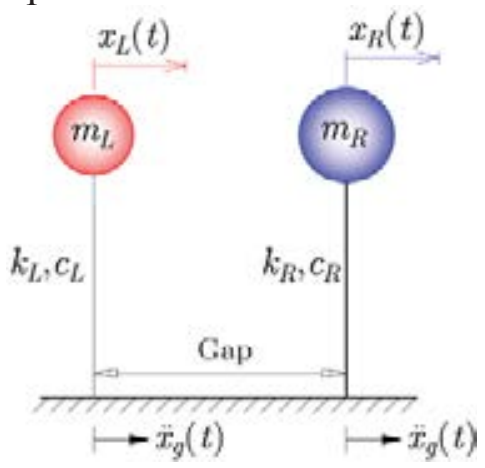

Figure 3: Representation of the two SDOF lumped mass models separated by a certain distance.

Table 1 presents the considered dynamic properties of each SDOF structural system according to [10].

\begin{tabular}{l|c|c}
\hline Structural properties & Flexible building & Stiffer building \\
\hline Mass $(\boldsymbol{k g})$ & $m_{L}=75000$ & $m_{R}=3000 \times 10^{3}$ \\
\hline Stiffness $(\boldsymbol{k N} / \boldsymbol{m})$ & $k_{L}=2056$ & $k_{R}=1.316 \times 10^{6}$ \\
\hline Natural period $(\boldsymbol{s})$ & $T_{L}=1.2$ & $T_{R}=0.3$ \\
\hline Damping coefficient $(\mathbf{k g} / \mathbf{s})$ & $c_{L}=39270$ & $c_{R}=6.283 \times 10^{6}$ \\
\hline Damping ratio $(\%)$ & $\xi_{L}=5$ & $\xi_{R}=5$ \\
\hline
\end{tabular}

Table 1: Structural properties of the adjacent buildings.

Equation 1 is modified to include the pounding force according to Equations 16 to 18 , becoming now, respectively, for the elastic and inelastic case as follows

$$
\begin{gathered}
m \ddot{x}(t)+c \dot{x}(t)+k x(t)+f_{P}(t)=-m \ddot{x}_{g}(t) \\
m \ddot{x}(t)+c \dot{x}(t)+a k_{0} x(t)+f_{r}^{*}[x(t), \dot{x}(t)]+f_{P}(t)=-m \ddot{x}_{g}(t),
\end{gathered}
$$

These structural systems will be subjected to a seismic ground motion, the El Centro's earthquake, whose acceleration signal is presented in Figure 4.

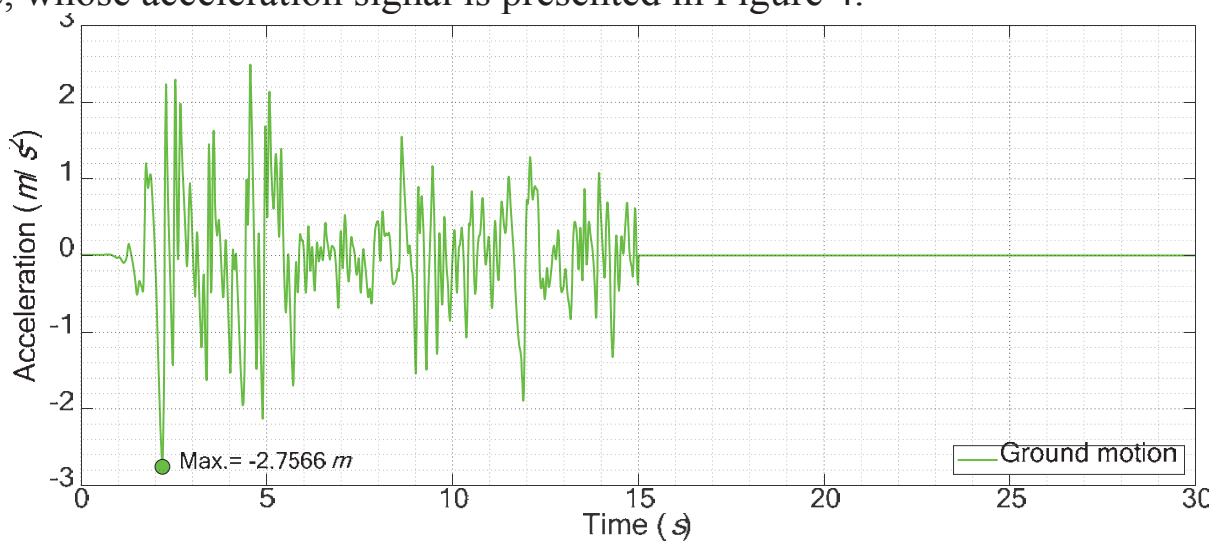

Figure 4: NS component of El Centro seismic accelerations - Station: El Centro, CA - Sta9; Imperial Valley-02 [45]. 
Equation 19 or 20 is used to emulate, respectively, the elastic and inelastic behavior of the considered structural systems. The hysteresis cases presented in section 2 will be considered. Table 2 presents the values considered to account for each case of hysteresis behavior. These values were based on the considerations given in [5].

\begin{tabular}{llcccccc}
\hline Case & Hysteresis behavior & $\boldsymbol{\alpha}$ & $\boldsymbol{\beta}_{\mathbf{1}}$ & $\boldsymbol{\beta}_{\mathbf{2}}$ & $\boldsymbol{\sigma}_{\mathbf{s}}$ & $\mathbf{R}_{\mathbf{s}}$ & $\boldsymbol{\lambda}_{\mathbf{s}}$ \\
\hline $\mathbf{0}$ & Plain & 50 & 0 & 0 & 1 & 0 & 0 \\
$\mathbf{1}$ & Stiffness degradation & 1 & 0 & 0 & 1 & 0 & 0 \\
$\mathbf{2}$ & Stiffness and strength degradation & 1 & 0.3 & 0.3 & 1 & 0 & 0 \\
$\mathbf{3}$ & Stiffness and strength degradation with pinching effect & 1 & 0.3 & 0.3 & 0.2 & 0.1 & 0 \\
\hline
\end{tabular}

Table 2: Non-linear hysteresis parameters for the structural system for different hysteresis behavior cases (in all cases: $\left.\eta_{1}=\eta_{2}=0.5, n_{W}=5, a=0.03, F_{Y L}=70 \mathrm{kN}, x_{Y L}=3.4 \mathrm{~cm}, F_{Y R}=7000 \mathrm{kN}, x_{Y R}=0.53 \mathrm{~cm}, \mu=10\right)$.

The pounding will be considered between the buildings' slabs and as implicitly mentioned the impact model will be the non-linear viscoelastic model developed by Jankowski ([30], [31]). The impact stiffness and the coefficient of restitution are, respectively, $2.75 \times 10^{9} \mathrm{~N} / \mathrm{m}^{3 / 2}$ and 0.65 [30].

A Matlab/Simulink [46] model was developed to simulate structural pounding between the elastic and inelastic SDOF systems subjected to the El Centro Earthquake. The Simulink model is represented in Figure 5 and contemplates the case of structural pounding between SDOF systems. The gap between the adjacent structures was varied: $0 \mathrm{~cm}, 3 \mathrm{~cm}, 5 \mathrm{~cm}, 10 \mathrm{~cm}$, and $15 \mathrm{~cm}$. To solve the differential equations of motion the Runge-Kutta of $4^{\text {th }}$ order was used with a fixed time step of $5 \times 10^{-4} \mathrm{~S}$.

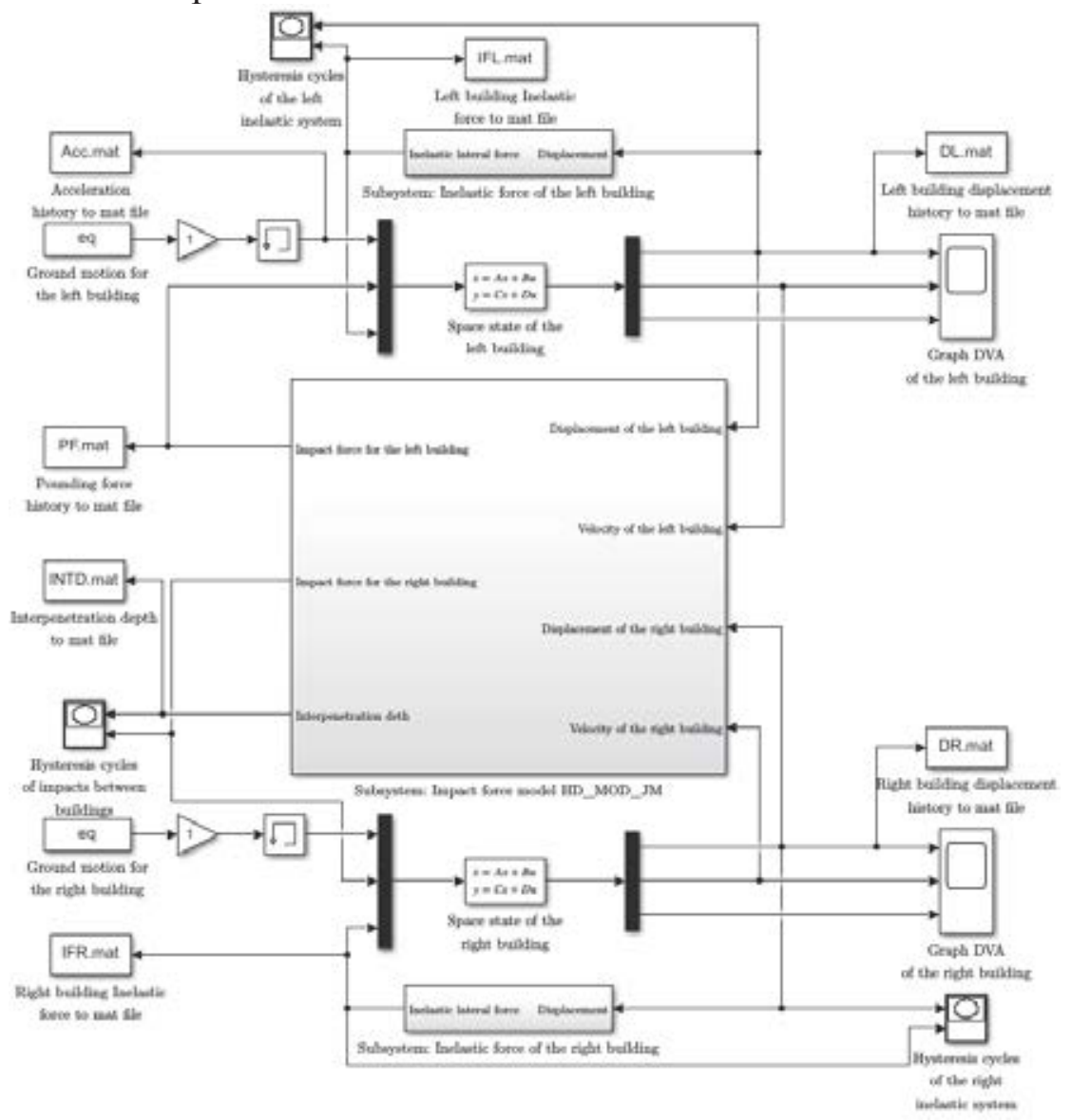

Figure 5: Layout of the macro Matlab/Simulink model using the non-linear viscoelastic impact model modified by Jankowski for pounding between non-linear systems. 


\section{RESULTS AND DISCUSSION}

For convenience, only the results concerning the gap size between the adjacent buildings of $0 \mathrm{~cm}$ and $3 \mathrm{~cm}$ are presented in graphical form, except for the hysteresis cycles for the four hysteresis cases in which only the worst case was presented, for the case of no gap distance. The graphs of the acceleration time-histories are presented only for case 3 of hysteresis behavior compared with the elastic case for both the gaps of $0 \mathrm{~cm}$ and $3 \mathrm{~cm}$. Nonetheless, Table 3 shows the peak values regarding displacements, velocities, accelerations, and pounding forces for each building and for the hysteresis cases considered and every value for the gap size studied. In addition, the number of impacts associated with each case is also presented. The percentages of increase or decrease depending on the cases being compared are shown below the peak values for better comparisons and understanding of the influence of the inelastic behavior in earthquake-induced pounding between buildings.

Attention is drawn to the fact that the gap size of $10 \mathrm{~cm}$ when the structural system has inelastic behavior does not appear in Table 3 since it didn't produce any impact and thus the responses are exactly the same as for the gap size of $15 \mathrm{~cm}$.

Figures 6 to 10 present the graphic results regarding the displacement time-histories of the two colliding structures with no space in between and the corresponding resulting pounding forces for the elastic case and the different hysteresis cases considered. In the same way Figures 11 to 15 present the same graphs mentioned but for the gap size of $3 \mathrm{~cm}$.

The graphs of Figures 16 to 20 present relevant comparisons between the displacements and pounding forces histories of the left structure, the most sensible to impacts and the ground motion for the different hysteresis behaviors considered and the elastic case.

The pounding cycles in Figure 21 are presented for both the elastic case and the different hysteresis cases considered.

Figure 22 shows the hysteresis cycles of each colliding building in comparison with the case of no pounding.

Finally, Figure 23 presents the acceleration response histories of both buildings for case 3 of hysteresis compared with the elastic case.
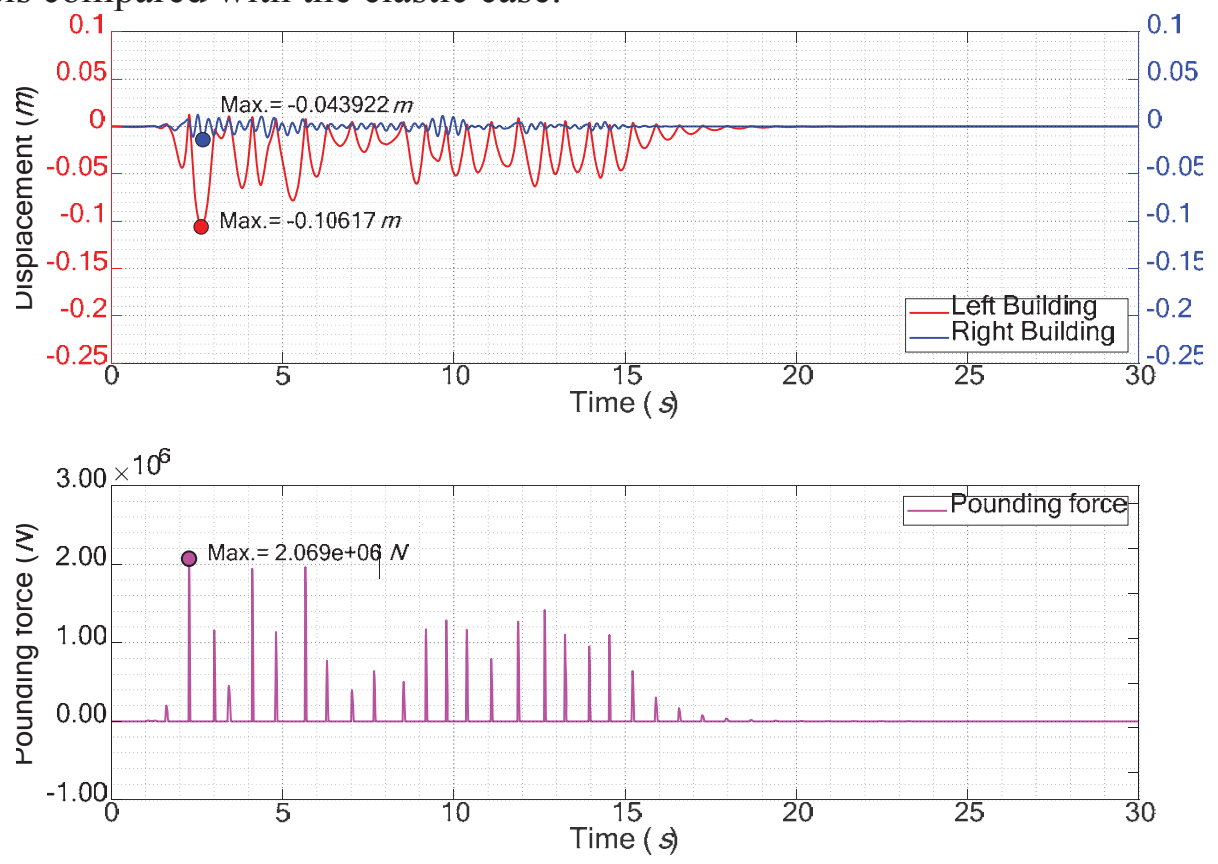

Figure 6: Displacements and pounding forces time-history responses for the elastic case of the representative structural systems with no gap in between. 

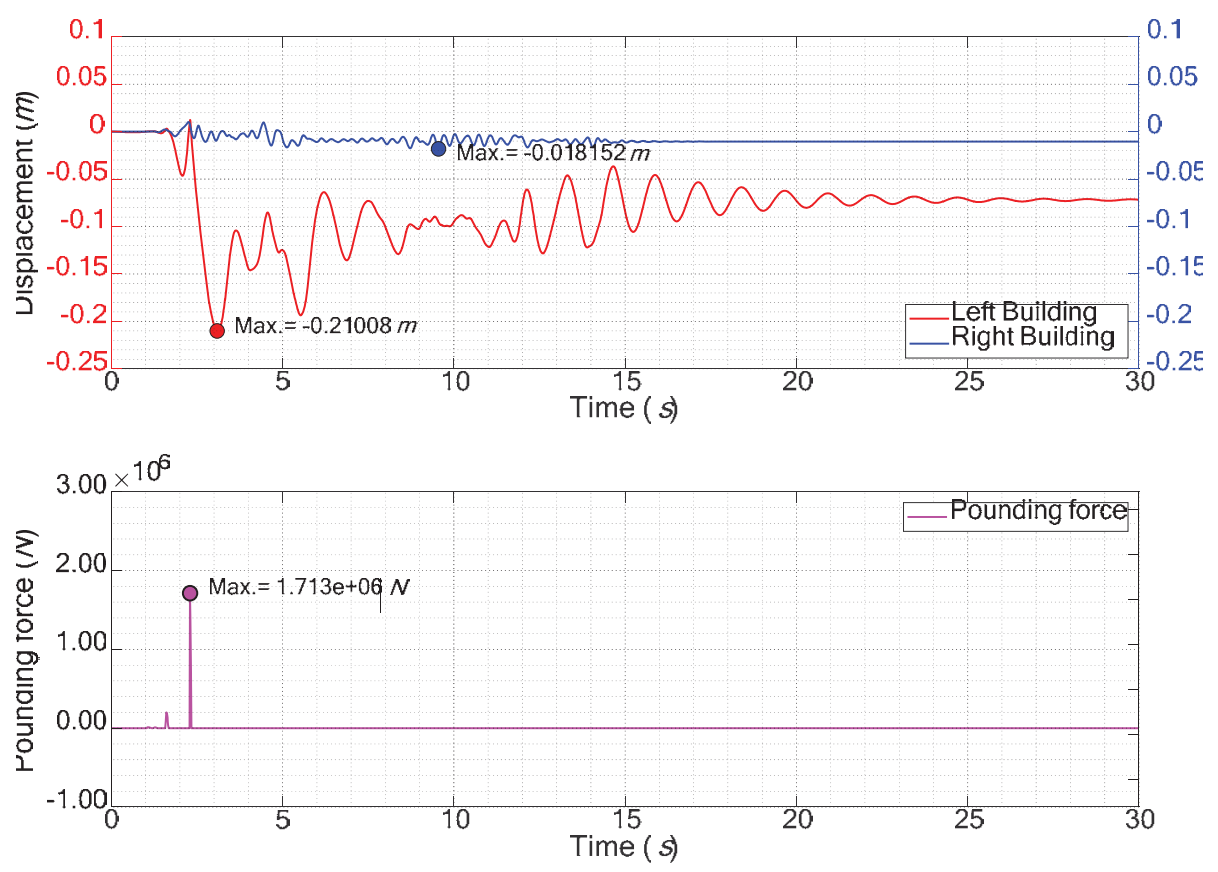

Figure 7: Displacements and pounding forces time-history responses for the hysteresis case 0 of the representative structural systems with no gap in between.
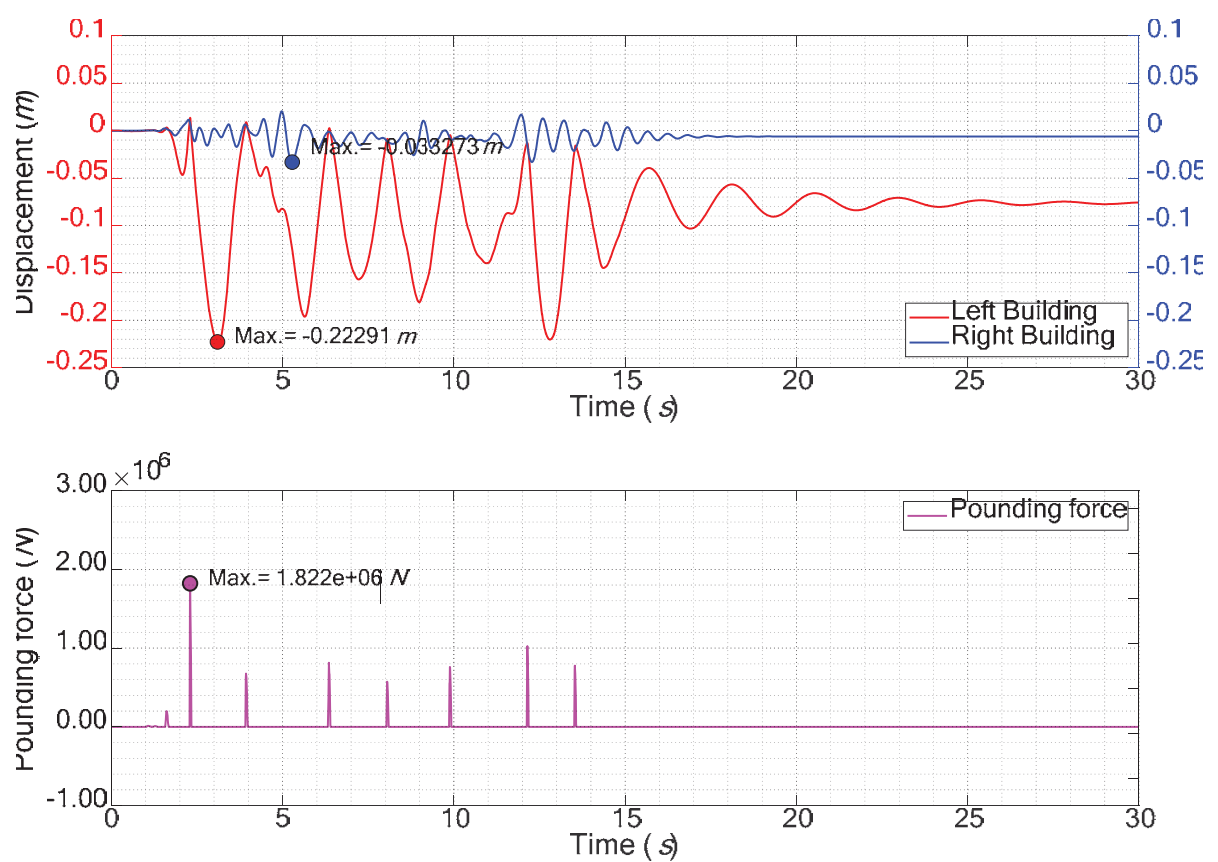

Figure 8: Displacements and pounding forces time-history responses for the hysteresis case 1 of the representative structural systems with no gap in between.

As expected, it is possible to verify the sensitiveness of the flexible building to both pounding forces and the ground motion. It is clear by the analysis of the results in Figures 6 to 15 that the inelastic cases present fewer impacts and the magnitude of the forces is smaller. However, the amplitude of the inelastic displacements, generally, exceeds the displacements in the elastic case, as can be validated by the peak values presented in Table 3 . This is particularly true when the responses involve pounding and for hysteresis cases with degradation fea- 
tures. When pinching is considered is possible to verify the largest inelastic displacements and magnitude of the pounding forces.

Analyzing the graphs from Figures 16 to 20 regarding the flexible building, one can verify that the case with no gap presents larger displacements and impact forces, as well as an increased number of impacts.

In the graphs of Figures 7 to 10 and 12 to 20 , it is possible to verify the permanent displacements in the rebound direction caused by the action of the ground excitation and aggravated by the impact forces.
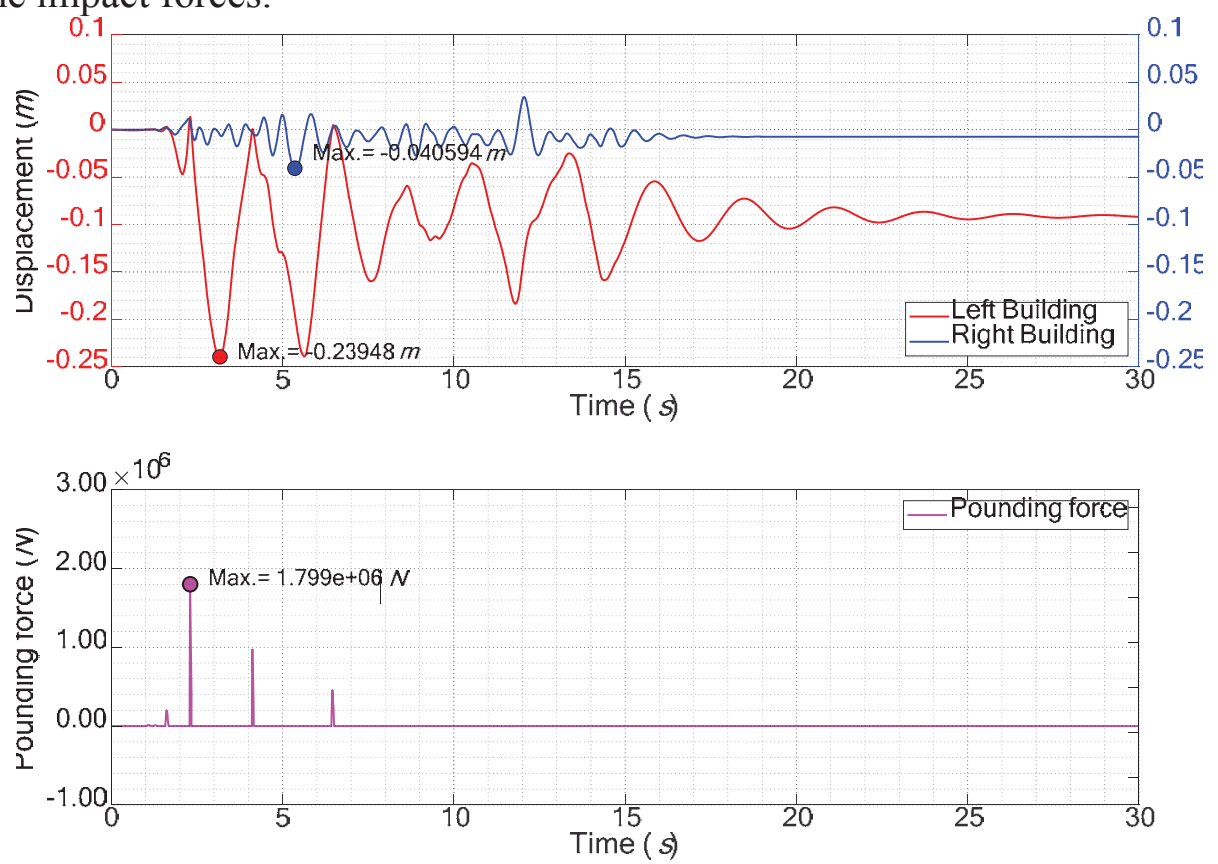

Figure 9: Displacements and pounding forces time-history responses for the hysteresis case 2 of the representative structural systems with no gap in between.
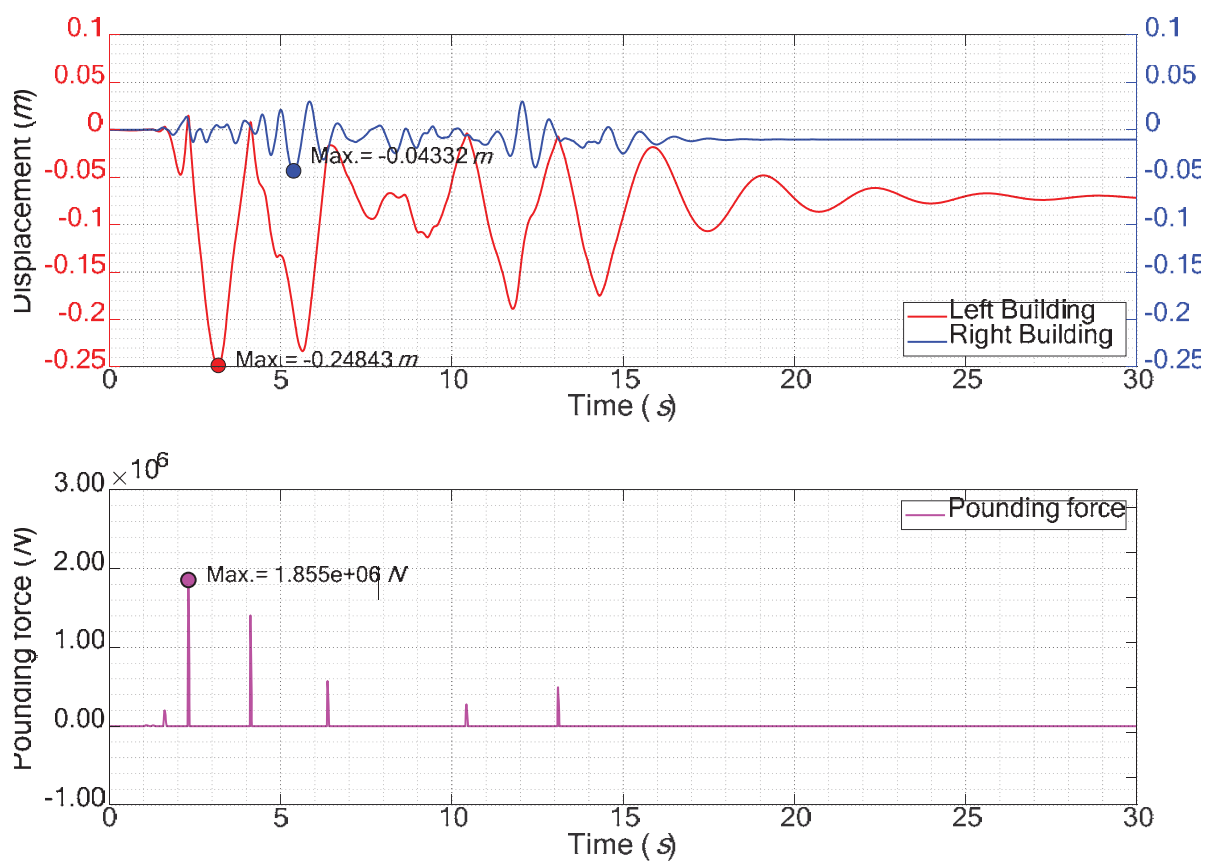

Figure 10: Displacements and pounding forces time-history responses for the hysteresis case 3 of the representative structural systems with no gap in between. 

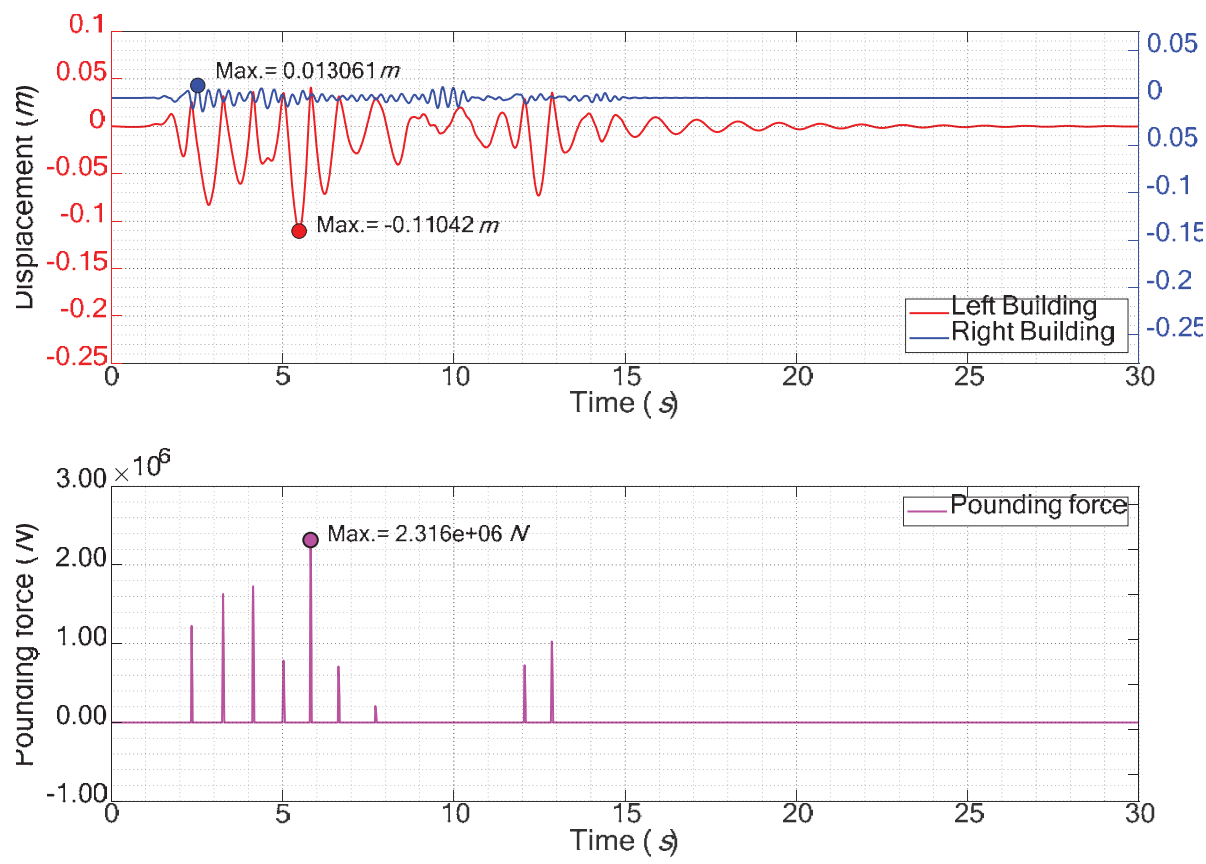

Figure 11: Displacements and pounding forces time-history responses for the elastic case of the representative structural systems separated by a distance of $3 \mathrm{~cm}$.
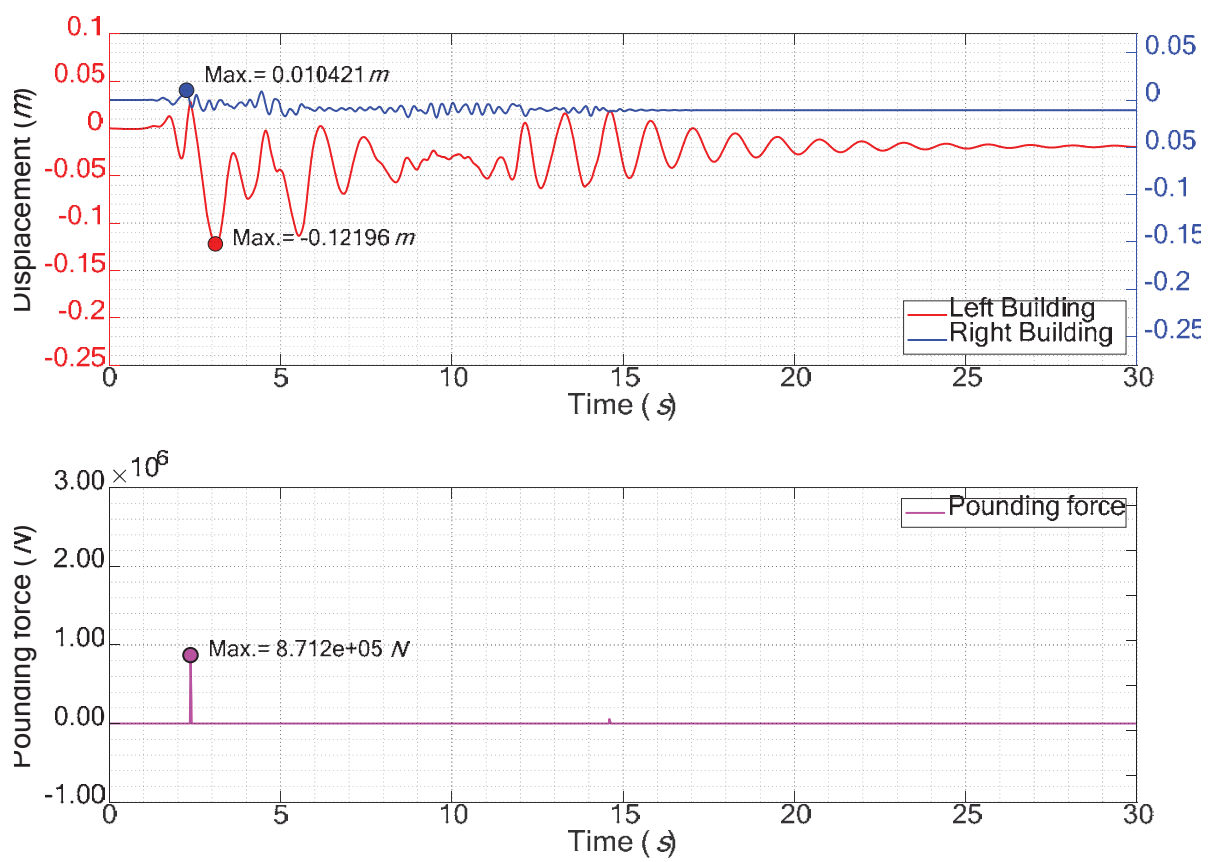

Figure 12: Displacements and pounding forces time-history responses for the hysteresis case 0 of the representative structural systems separated by a distance of $3 \mathrm{~cm}$.

These permanent displacements are most visible in the flexible structure which proves once more the sensitiveness of the flexible building to pounding forces.

The residual displacements increase as the gap between the adjacent structures decreases, and since the number of impacts and its magnitude increases for these scenarios then it proves and supports the influence that the pounding forces have when inelastic behavior is considered. Such a fact would not be noticed when elastic behavior is considered. 

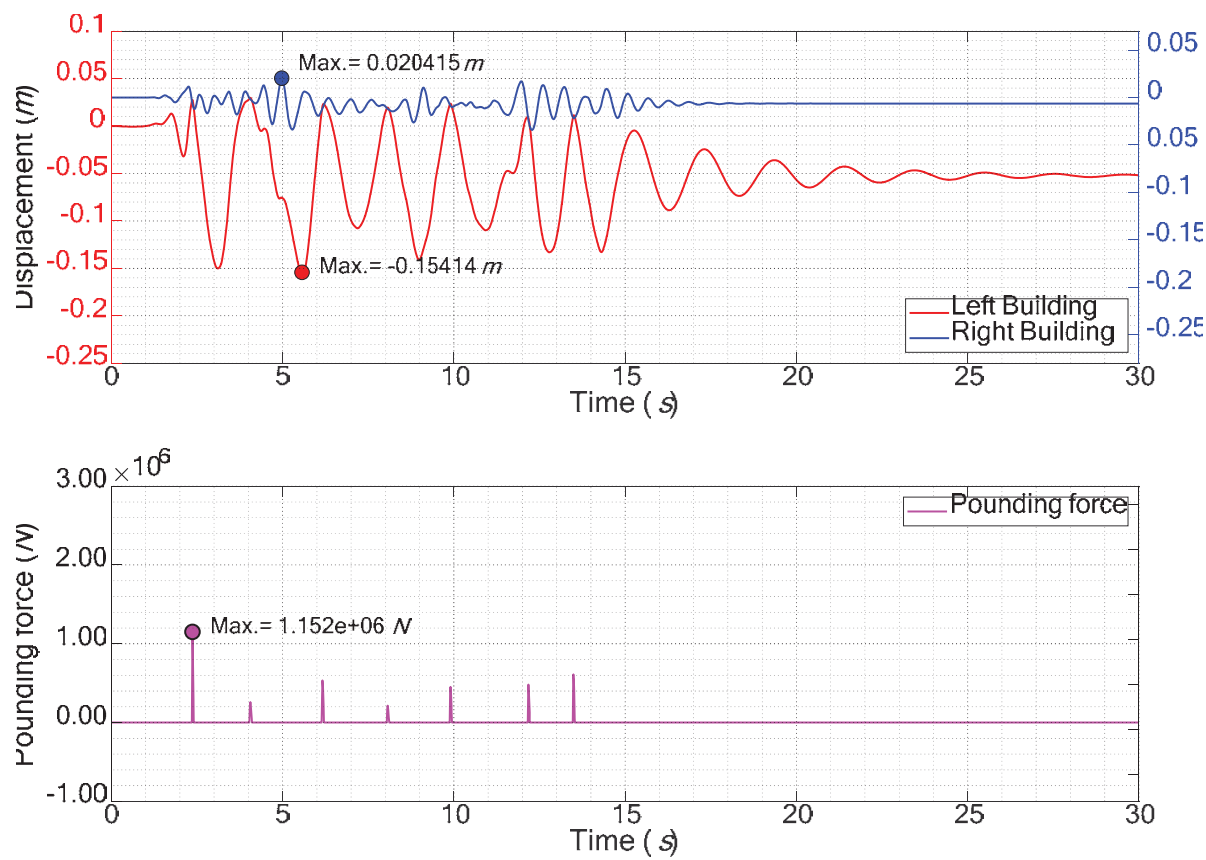

Figure 13: Displacements and pounding forces time-history responses for the hysteresis case 1 of the representative structural systems separated by a distance of $3 \mathrm{~cm}$.
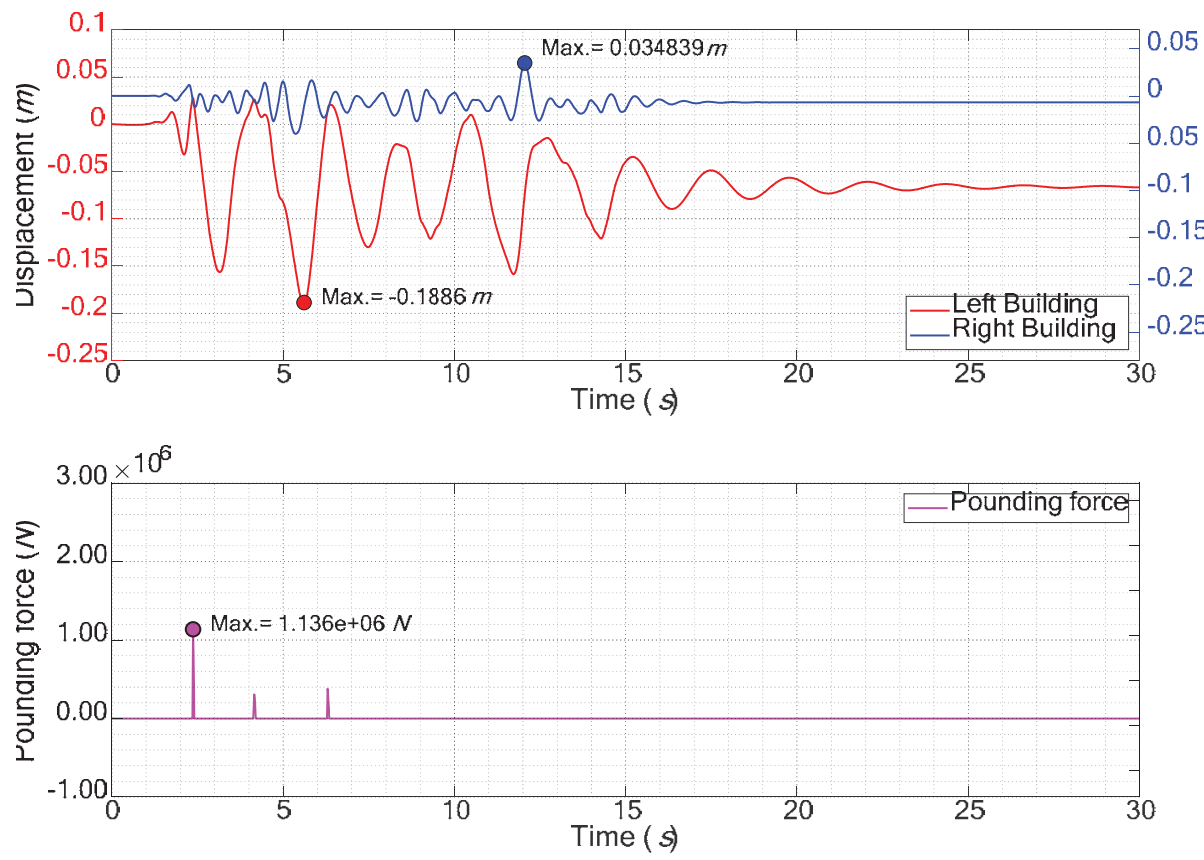

Figure 14: Displacements and pounding forces time-history responses for the hysteresis case 2 of the representative structural systems separated by a distance of $3 \mathrm{~cm}$.

It is not clear for which case of hysteresis behavior the unrecoverable displacements are bigger since it also depends on the separation distance between the adjacent buildings. Nevertheless, these tend to be slightly bigger in case 2 of hysteresis behavior, when stiffness and strength degradation are considered.

Observing the graphs of Figure 21 regarding the pounding cycles, it is evident the difference between the magnitude of impacts when elastic and inelastic cases are considered. The number of cycles for the elastic case is also bigger for the inelastic cases. The number of im- 
pacts is smaller for the hysteresis case 0 and bigger for the cases where stiffness degradation, strength deterioration, and the pinching effect are considered. In addition, the increase in the gap size decreased the magnitude of impacts as already mentioned by the observation of other graphs. Hence, with a few exceptions within the inelastic cases, case 3 presented slightly higher magnitudes for the impact forces.

The hysteresis loops for the different cases considered and for the scenario of no gap confirm the conclusions withdrawn previously, viz., the presence of permanent deformations in the rebound direction in the left building.
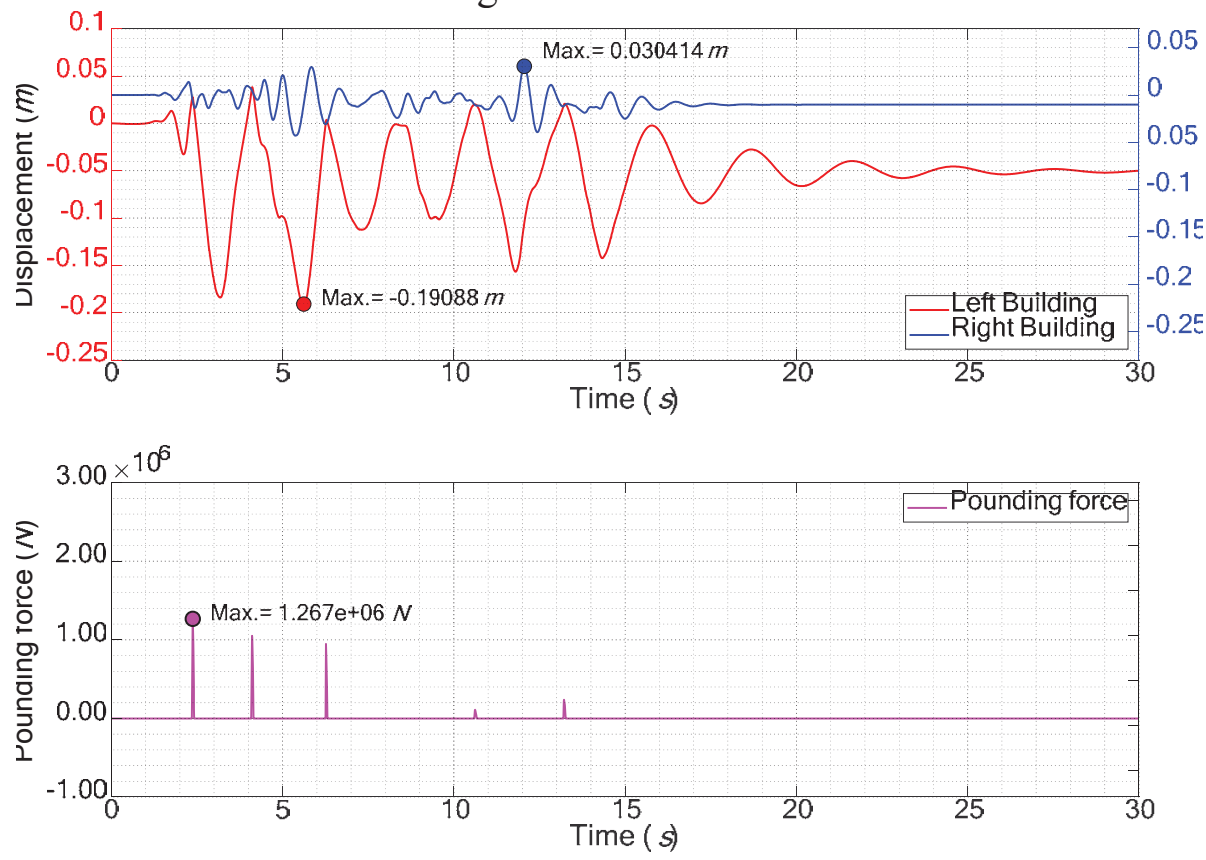

Figure 15: Displacements and pounding forces time-history responses for the hysteresis case 3 of the representative structural systems separated by a distance of $3 \mathrm{~cm}$.
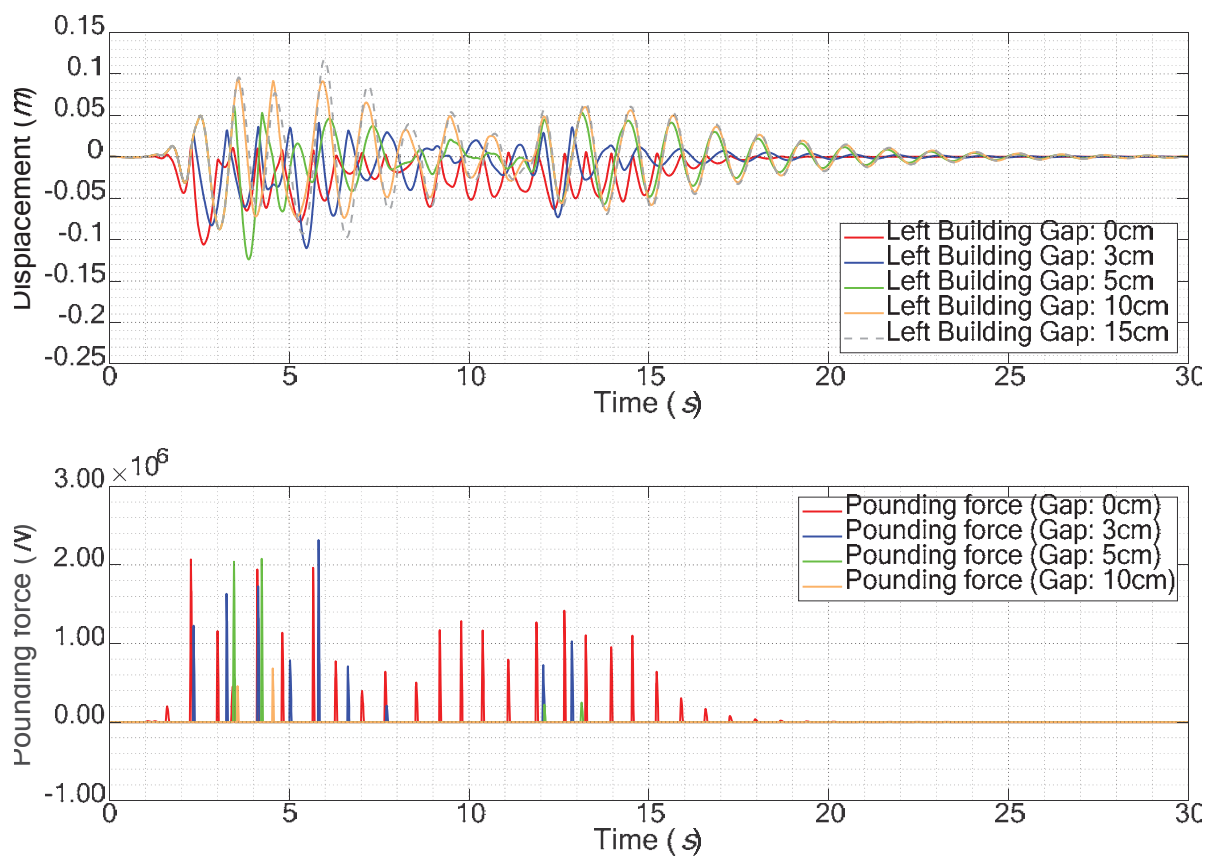

Figure 16: Comparison of the displacements and pounding forces time-history responses for the elastic case of the left building for different gap sizes. 

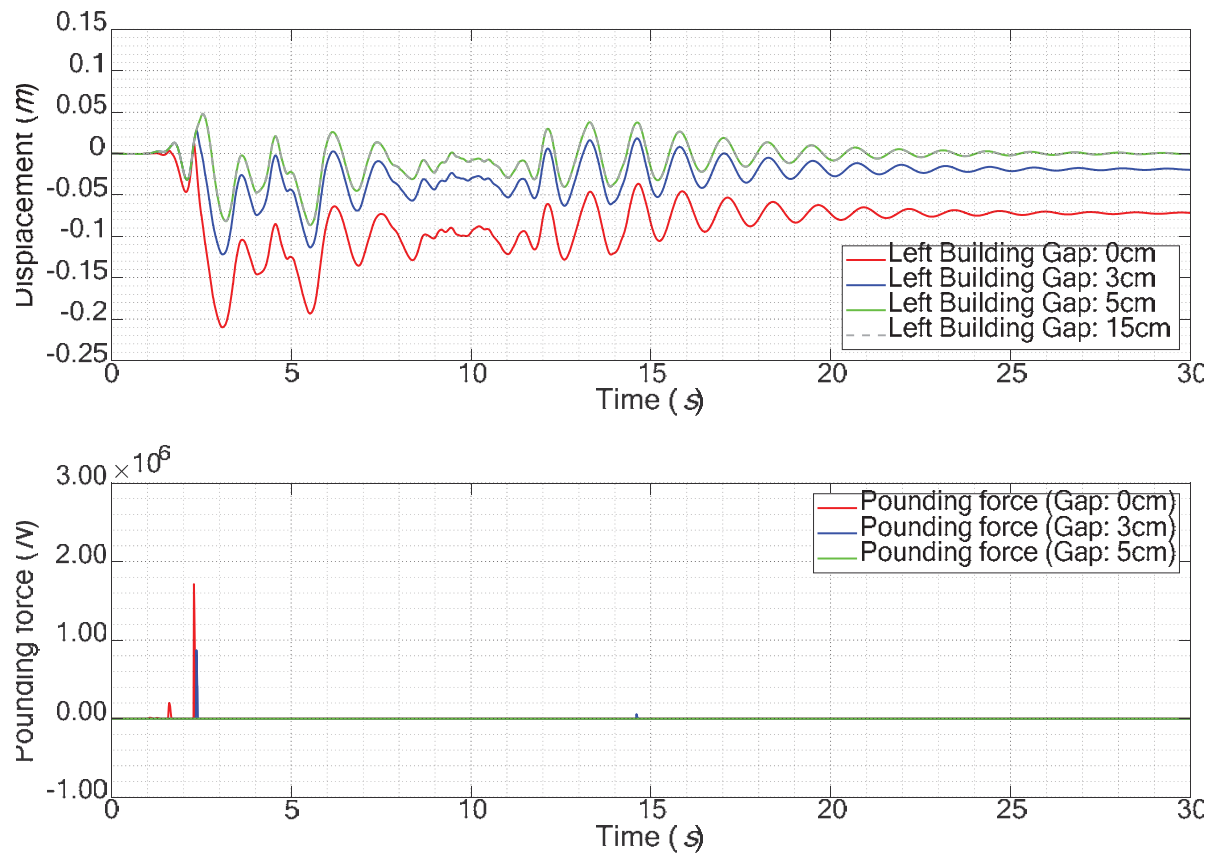

Figure 17: Comparison of the displacements and pounding forces time-history responses for the hysteresis case 0 of the left building for different gap sizes.
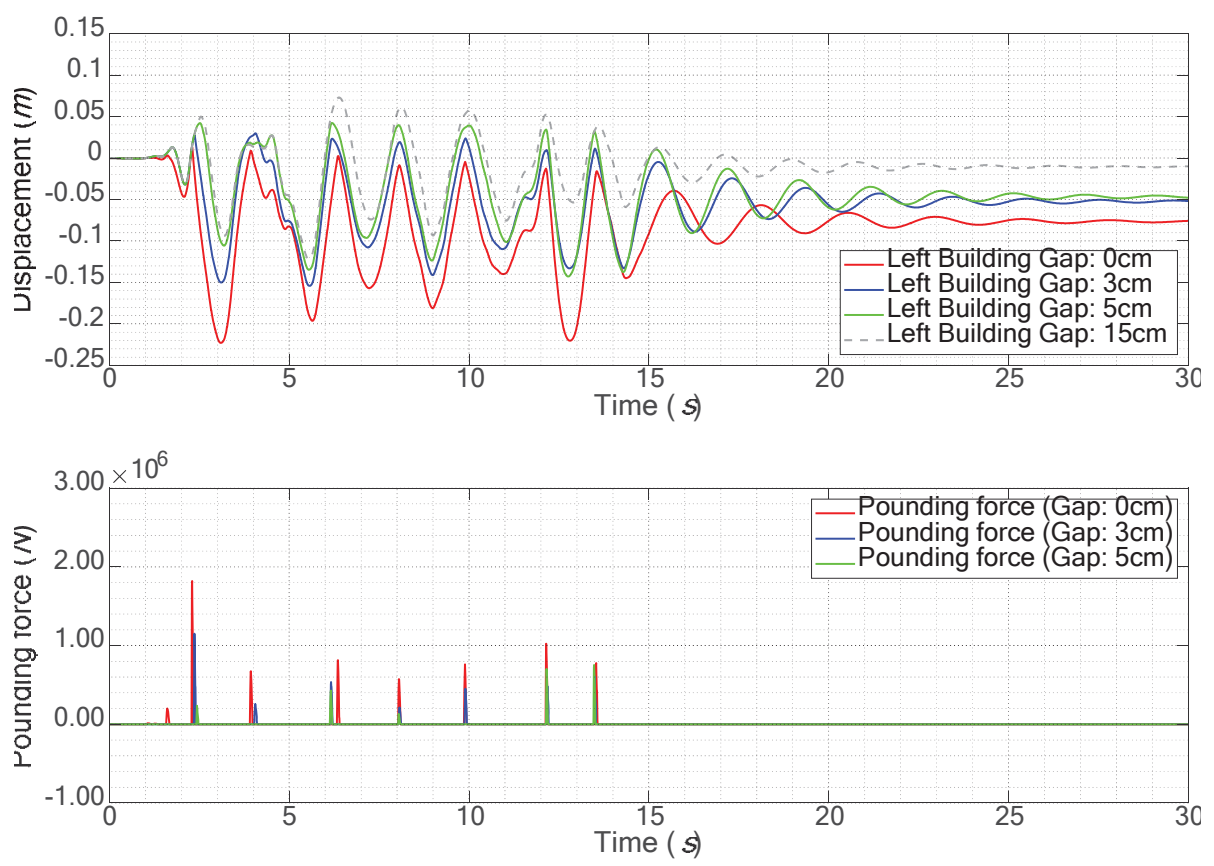

Figure 18: Comparison of the displacements and pounding forces time-history responses for the hysteresis case 1 of the left building for different gap sizes.

The hysteresis cycles also reveal that pounding has very little or no effect on the right structure. The hysteresis loops when pounding is considered are almost coincident showing very little deviation from the case with no pounding.

Table 3 also shows that the stiffer structure with inelastic behavior generally presents percentages of increase or decrease of the peak displacement with respect to the case with no pounding, which are approximately zero concerning the hysteresis cases and the gap sizes presenting impacts, viz., $3 \mathrm{~cm}$ and $5 \mathrm{~cm}$. The exception is the scenario without space in be- 
tween the structures that present an increase of the peak displacement in every hysteresis case. This increase corresponds to the case presented in Figure 22.

Table 3 also shows that in the elastic case the stiffer structure exhibits a reduction of the peak displacements for every gap size when pounding is considered.

Regarding the acceleration responses in Figures 23 and 24, it is possible to verify the reduction of the number and magnitude of the acceleration spikes of both the left and right structures when the inelastic behavior (Case 3 of hysteresis behavior) is considered with respect to the elastic case.
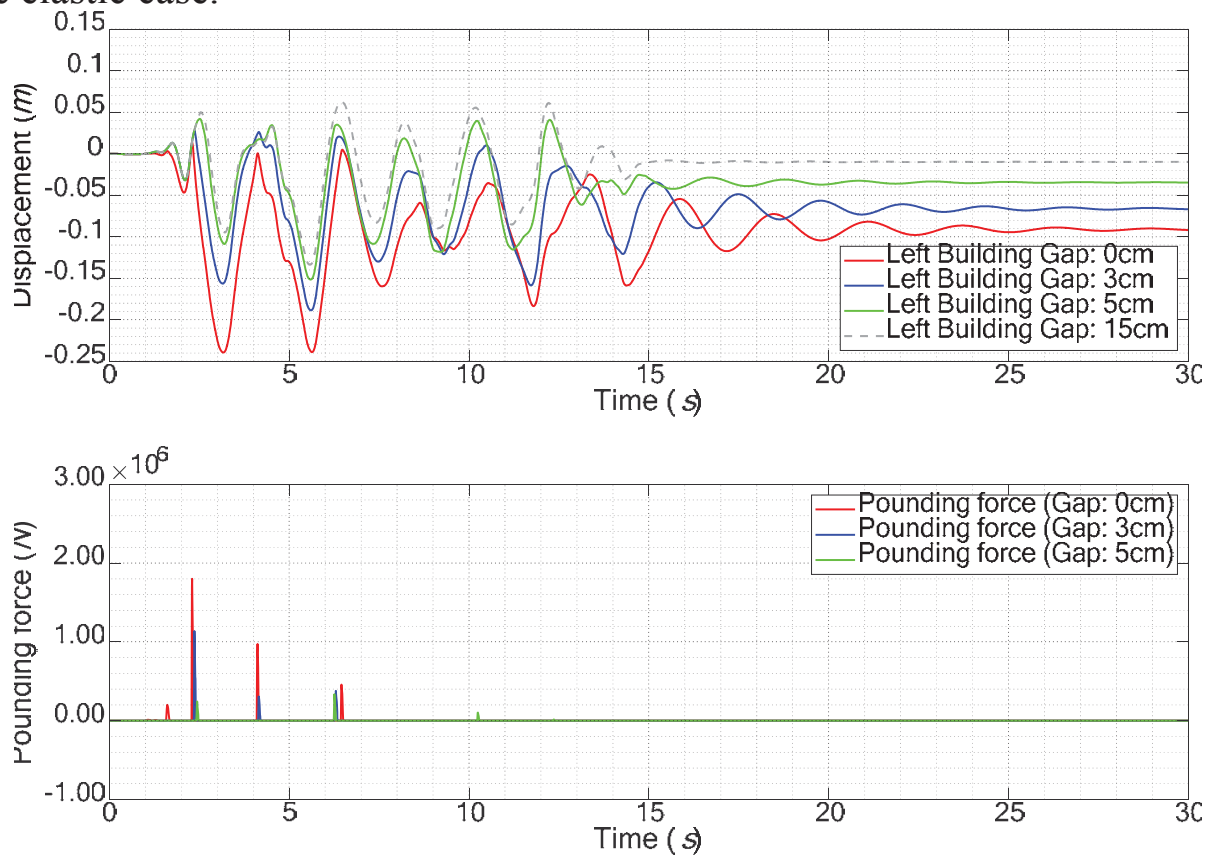

Figure 19: Comparison of the displacements and pounding forces time-history responses for the hysteresis case 2 of the left building for different gap sizes.
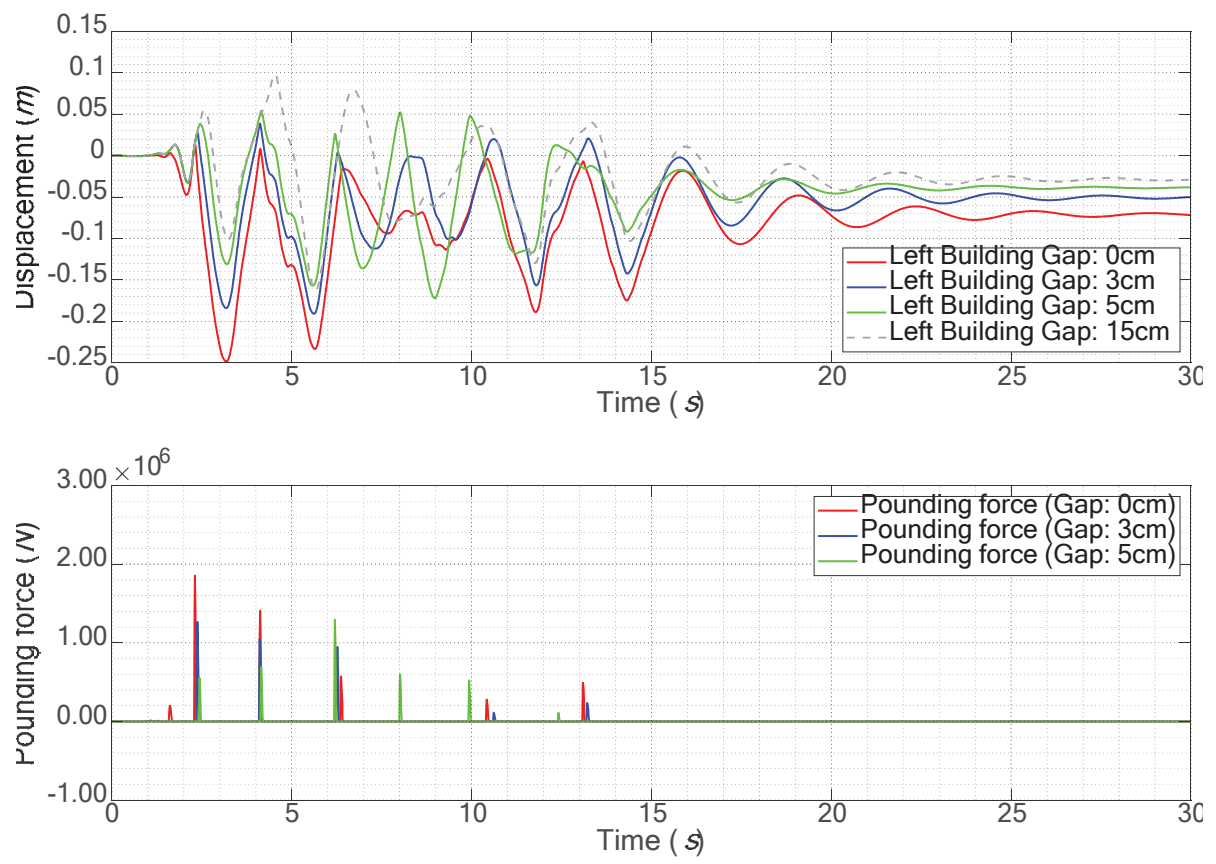

Figure 20: Comparison of the displacements and pounding forces time-history responses for the hysteresis case 3 of the left building for different gap sizes. 
(a)

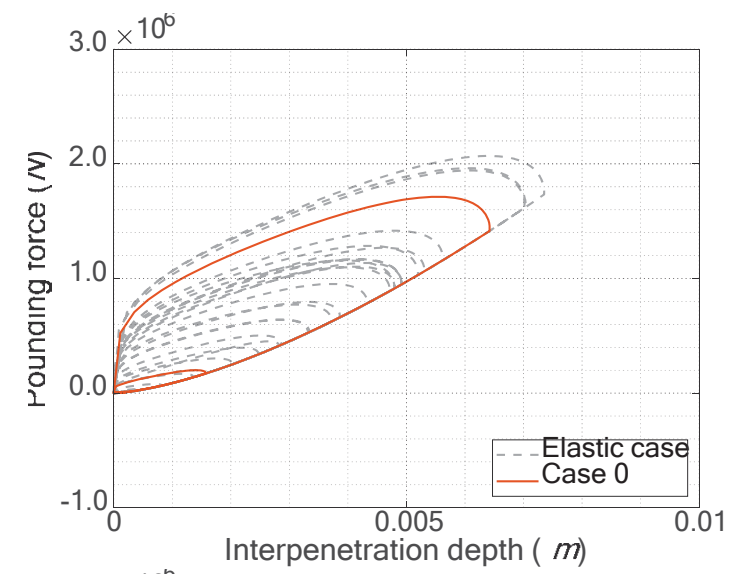

(c)

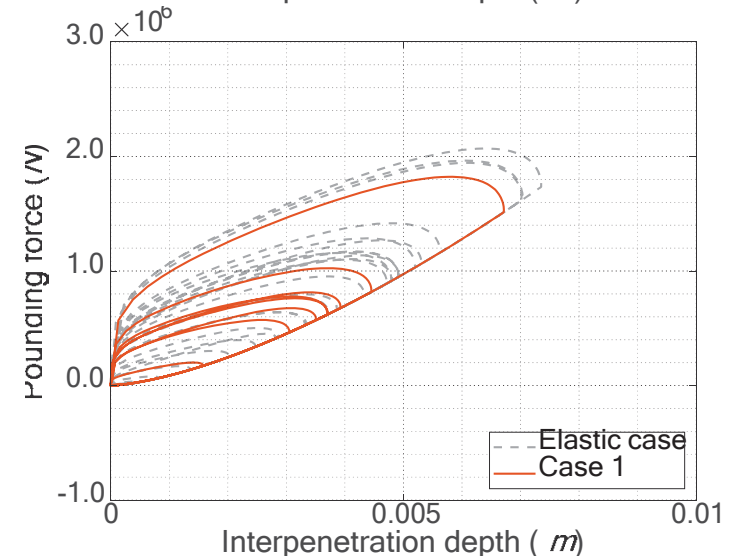

(e)

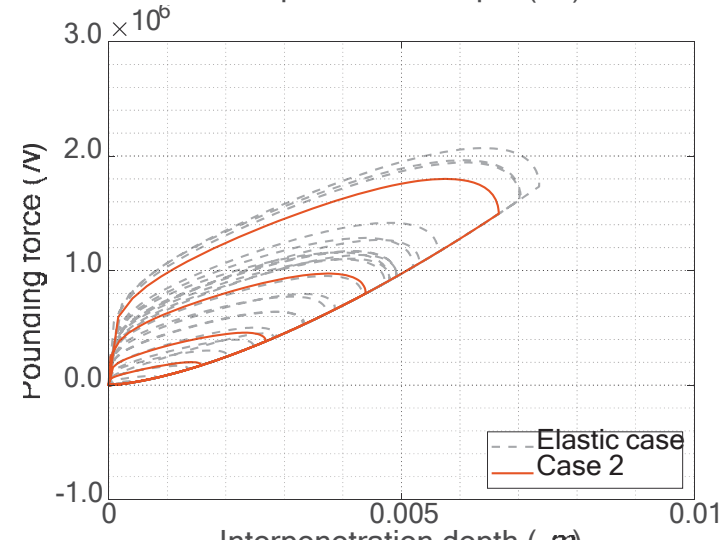

(g)

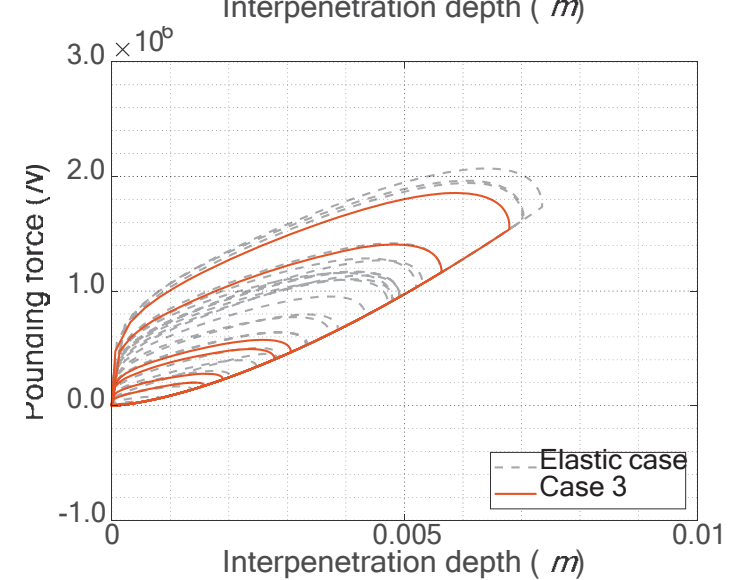

(b)

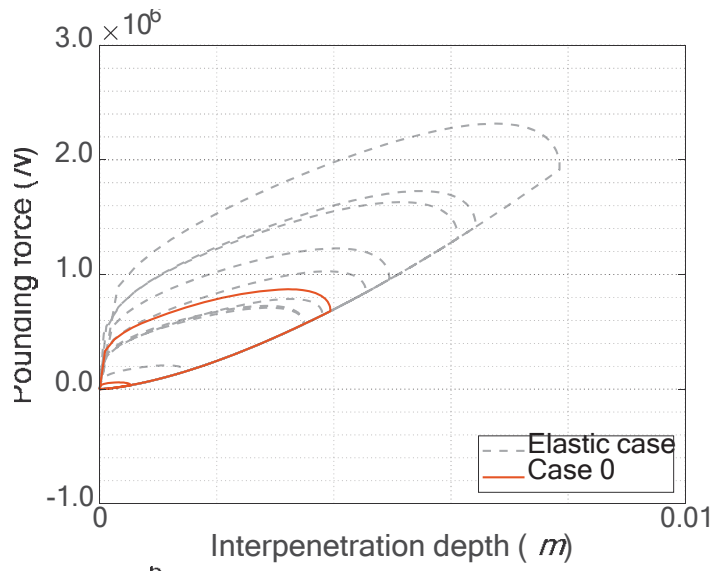

(d)

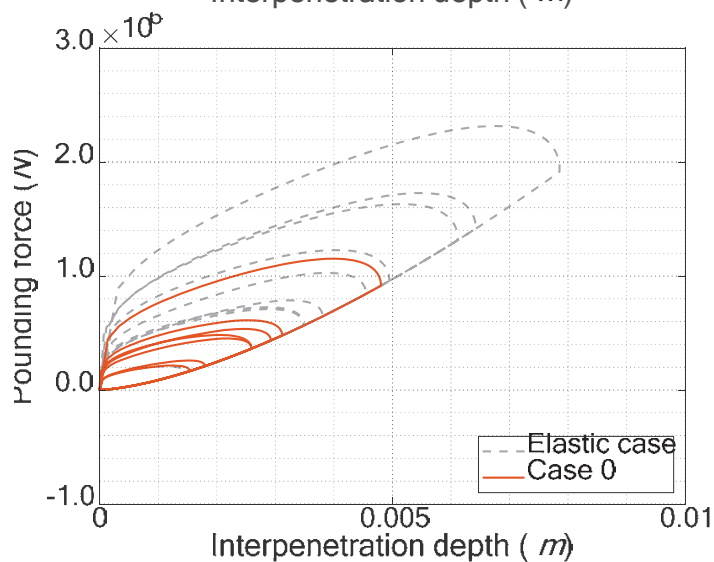

(f)

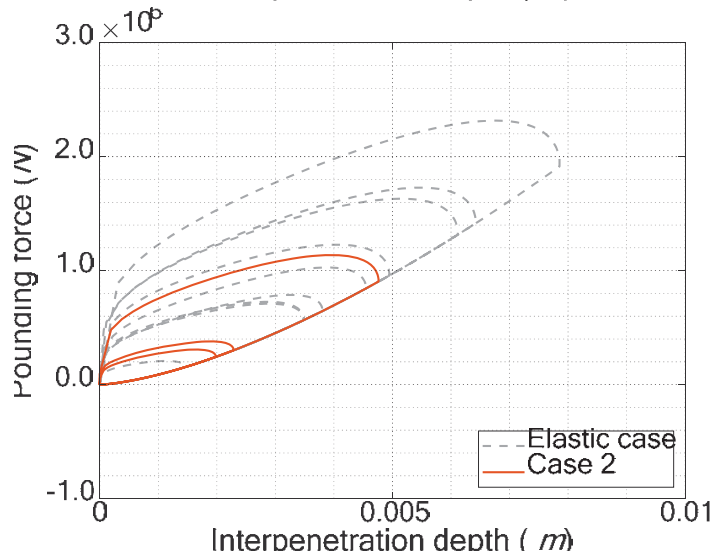

(h)

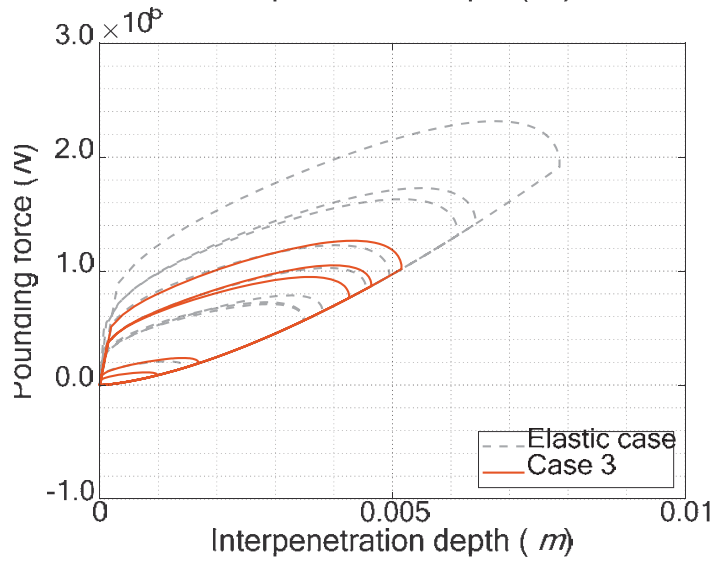

Figure 21: Pounding cycles for the hysteresis cases of the frame structures compared to the elastic case: (a), (c), (e), and (g) $0 \mathrm{~cm}$; (b), (d), (f) and (h) $3 \mathrm{~cm}$. 
(a)

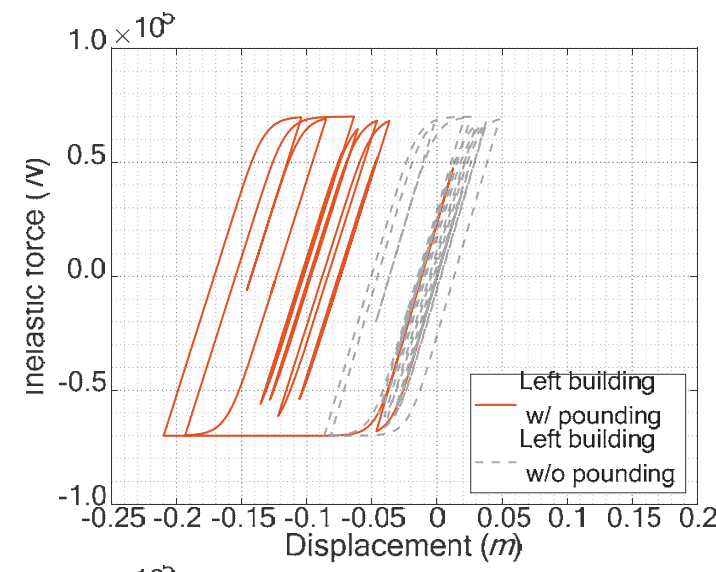

(c)

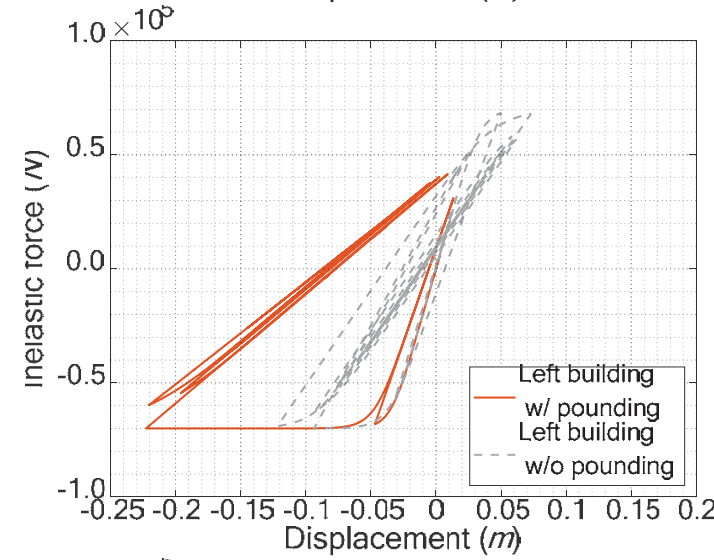

(e)

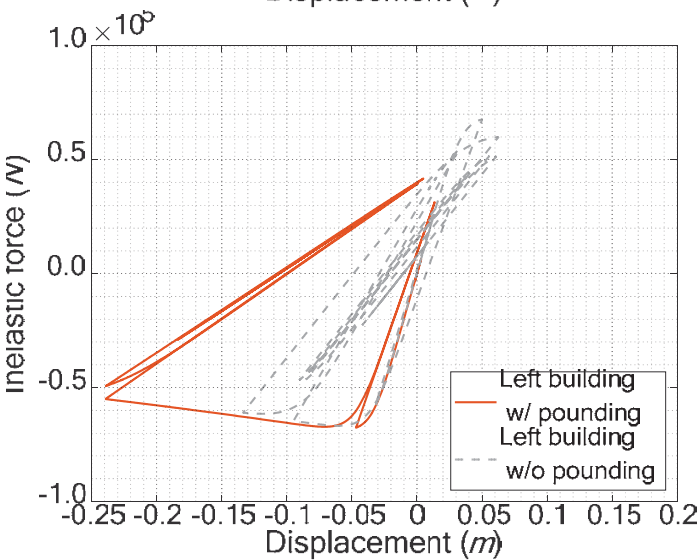

(g)

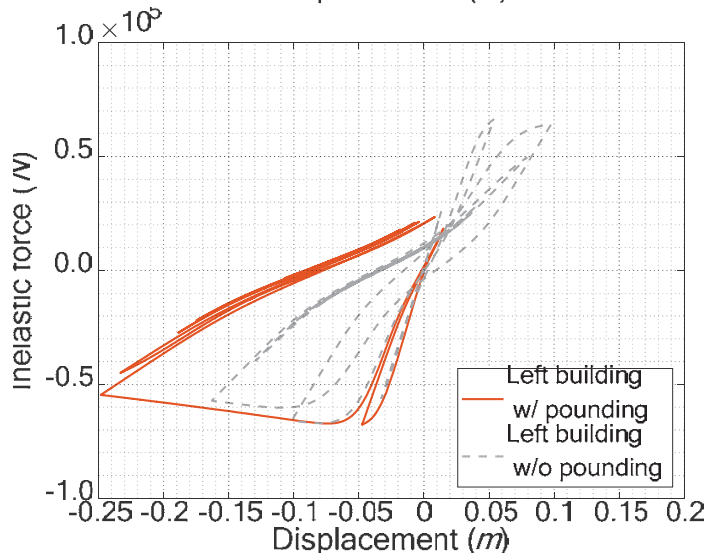

(b)

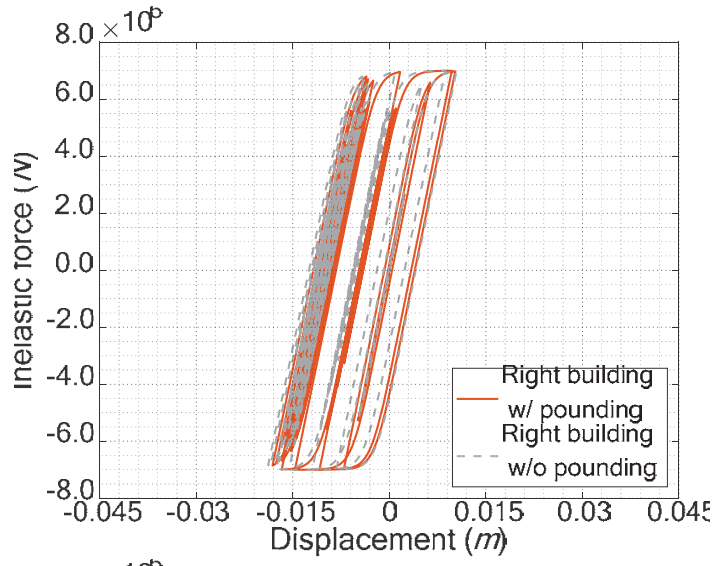

(d)

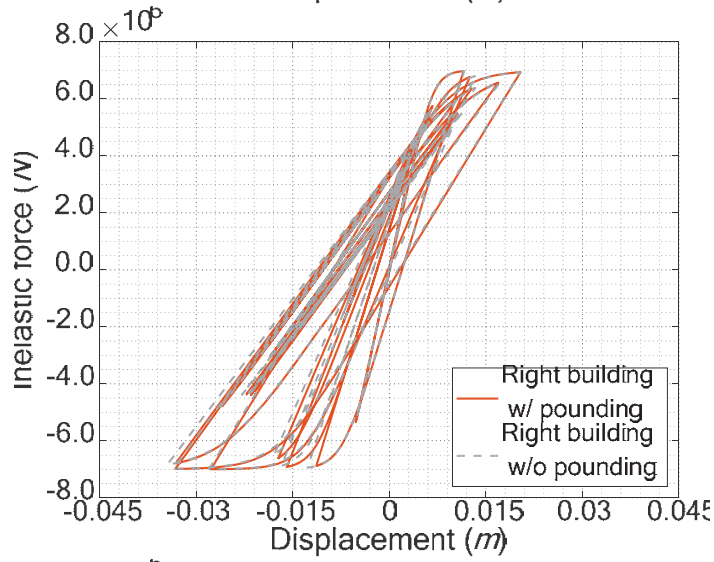

(f)
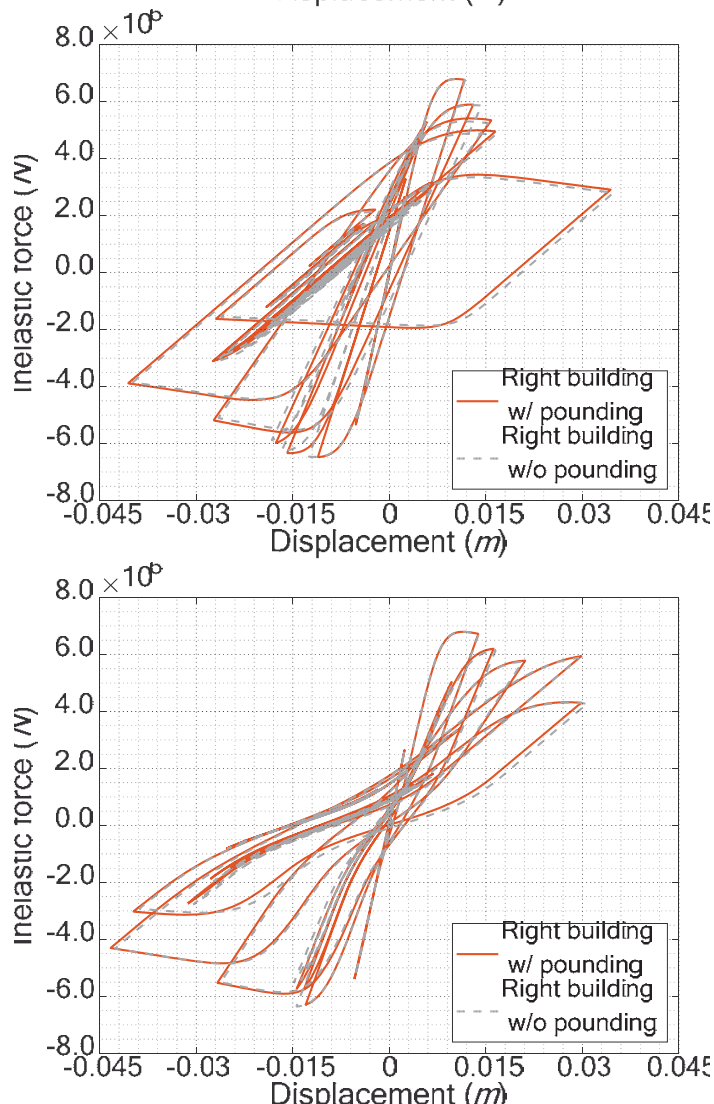

Figure 22: Hysteresis cycles when the structural systems have no gap in between: (a) and (b) Case 0; (c) and (d) Case 1; (e) and (f) Case 2; (g) and (h) Case 3. 

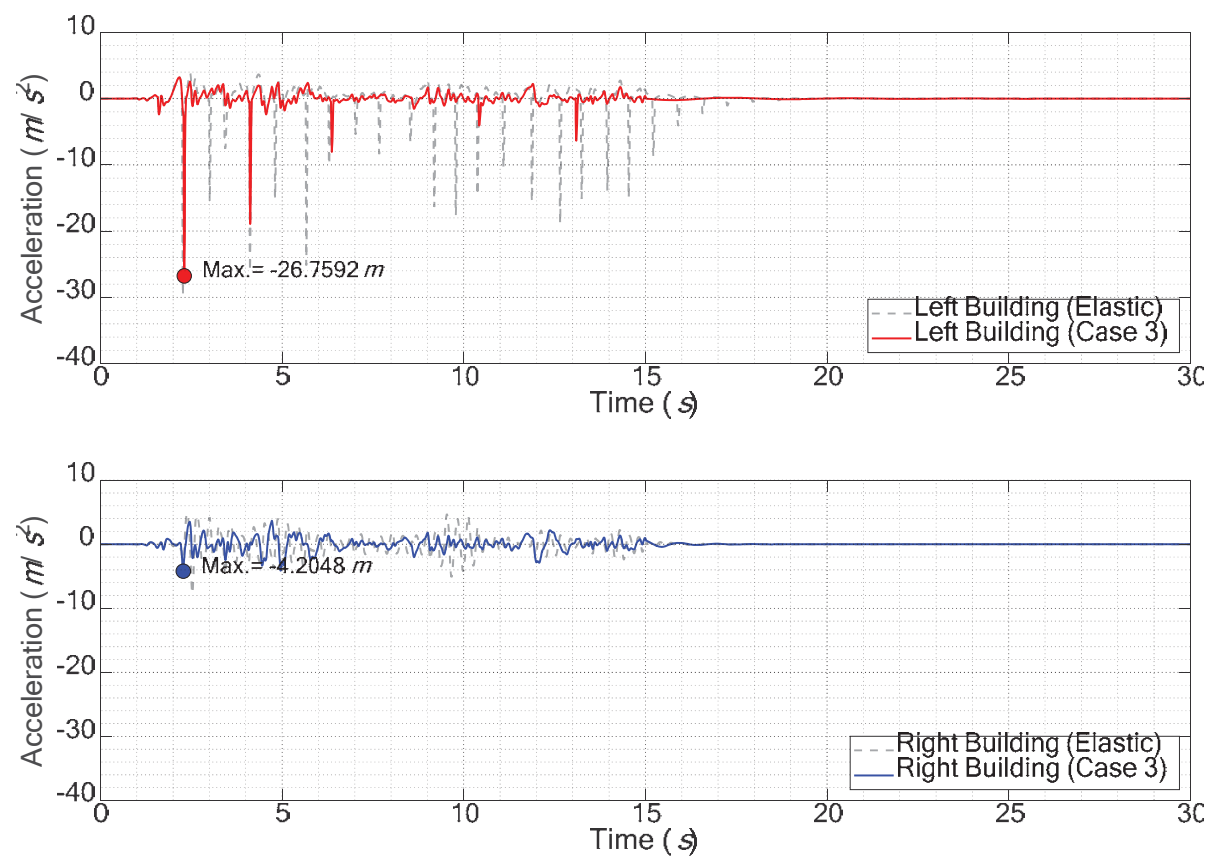

Figure 23: Acceleration time-history responses for the hysteresis case 3 of the structural systems with no space in between.
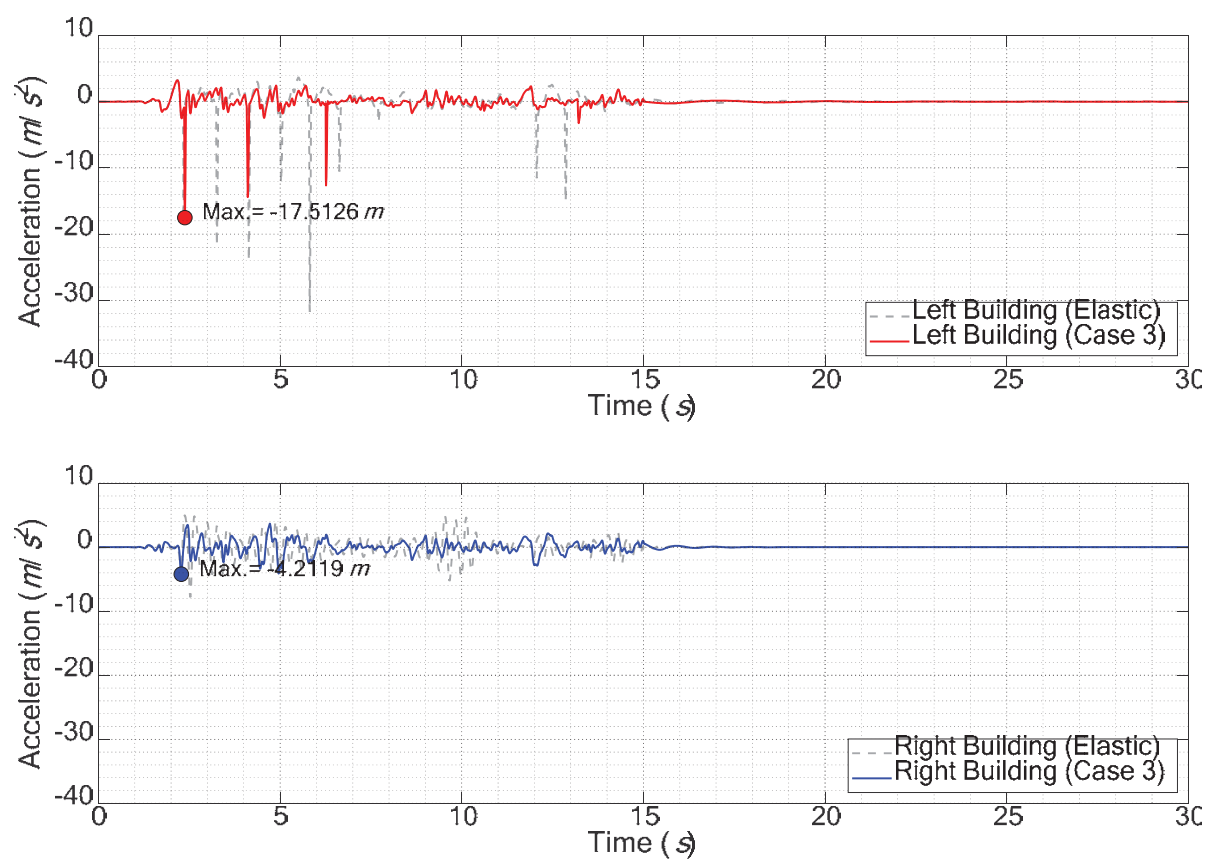

Figure 24: Acceleration time-history responses for the hysteresis case 3 of the structural systems separated by a distance of $3 \mathrm{~cm}$.

From the peak acceleration values presented in Table 3 with particular emphasis on the flexible structure, it is possible to see the influence of the pounding forces in the large increases of the peak acceleration values for both the elastic and inelastic cases (except for the case $0 \mathrm{~cm}$ with $5 \mathrm{~cm}$ of gap size that presented no impact - see Figure 17). However, the acceleration spikes are smaller when the hysteresis cases are considered as can be seen in the percentages in green color that present negative values. 
Folhento P. Pedro, Barros C. Rui and Braz-César T. Manuel

\begin{tabular}{|c|c|c|c|c|c|c|c|c|c|}
\hline \multirow{2}{*}{$\begin{array}{l}\text { Behavior of } \\
\text { frame struc- } \\
\text { ture }\end{array}$} & \multirow{2}{*}{$\begin{array}{l}\text { Gap } \\
(\mathrm{cm})\end{array}$} & \multicolumn{7}{|c|}{ Peak absolute values } & \multirow{2}{*}{$\begin{array}{c}\text { № of im- } \\
\text { pacts }\end{array}$} \\
\hline & & $\begin{array}{l}x_{L} \\
(m)\end{array}$ & $\begin{array}{l}x_{R} \\
(m)\end{array}$ & $\begin{array}{c}\dot{x}_{L} \\
(\mathrm{~m} / \mathrm{s})\end{array}$ & $\begin{array}{c}\dot{x}_{R} \\
(m / s)\end{array}$ & $\begin{array}{c}\ddot{x}_{L} \\
\left(m / s^{2}\right)\end{array}$ & $\begin{array}{c}\ddot{x}_{R} \\
\left(\mathrm{~m} / \mathrm{s}^{2}\right)\end{array}$ & $\begin{array}{c}F_{P} \\
(k N)\end{array}$ & \\
\hline \multirow{5}{*}{$\begin{array}{l}\text { Linear } \\
\text { Elastic }\end{array}$} & 15 & 0.118 & 0.133 & 0.598 & -0.312 & -4.588 & -7.961 & 0 & 0 \\
\hline & 10 & $\begin{array}{c}0.094 \\
(-20 \%)\end{array}$ & $\begin{array}{c}0.013 \\
(-90 \%)\end{array}$ & $\begin{array}{l}0.579 \\
(-3 \%)\end{array}$ & $\begin{array}{c}-0.312 \\
(0 \%)\end{array}$ & $\begin{array}{l}-13.837 \\
(202 \%)\end{array}$ & $\begin{array}{c}-7.961 \\
(0 \%)\end{array}$ & 683.716 & 2 \\
\hline & 5 & $\begin{array}{c}-0.124 \\
(5 \%)\end{array}$ & $\begin{array}{c}0.013 \\
(-90 \%)\end{array}$ & $\begin{array}{l}0.694 \\
(16 \%)\end{array}$ & $\begin{array}{c}-0.312 \\
(0 \%)\end{array}$ & $\begin{array}{l}-29.877 \\
(551 \%)\end{array}$ & $\begin{array}{c}-7.961 \\
(0 \%)\end{array}$ & 2077.72 & 4 \\
\hline & 3 & $\begin{array}{c}-0.110 \\
(-6 \%)\end{array}$ & $\begin{array}{c}0.013 \\
(-90 \%) \\
\end{array}$ & $\begin{array}{l}0.704 \\
(18 \%) \\
\end{array}$ & $\begin{array}{c}-0.309 \\
(-1 \%)\end{array}$ & $\begin{array}{l}-31.743 \\
(592 \%)\end{array}$ & $\begin{array}{c}-7.818 \\
(-2 \%)\end{array}$ & 2315.8 & 9 \\
\hline & 0 & $\begin{array}{l}-0.106 \\
(-10 \%) \\
\end{array}$ & $\begin{array}{l}-0.044 \\
(-67 \%)\end{array}$ & $\begin{array}{c}-0.589 \\
(-1 \%)\end{array}$ & $\begin{array}{l}-0.296 \\
(-5 \%)\end{array}$ & $\begin{array}{l}-29.746 \\
(548 \%)\end{array}$ & $\begin{array}{c}-7.693 \\
(-3 \%)\end{array}$ & 2069.01 & 29 \\
\hline \multirow{4}{*}{$\begin{array}{l}\text { Non-linear } \\
\text { Inelastic } \\
\text { (Case 0) }\end{array}$} & 15 & -0.087 & 0.010 & 0.375 & -0.197 & -3.441 & -4.584 & 0 & 0 \\
\hline & 5 & $\begin{array}{c}-0.087 \\
(0 \%) \\
(-30 \%)\end{array}$ & $\begin{array}{c}0.010 \\
(0 \%) \\
(-22 \%)\end{array}$ & $\begin{array}{c}0.375 \\
(0 \%) \\
(-46 \%)\end{array}$ & $\begin{array}{c}-0.197 \\
(0 \%) \\
(-37 \%)\end{array}$ & $\begin{array}{c}-3.441 \\
(0 \%) \\
(-88 \%)\end{array}$ & $\begin{array}{c}-4.584 \\
(0 \%) \\
(-42 \%)\end{array}$ & $\begin{array}{c}0 \\
0 \\
(-100 \%)\end{array}$ & $\begin{array}{c}0 \\
0 \\
(-100 \%)\end{array}$ \\
\hline & 3 & $\begin{array}{l}-0.122 \\
(41 \%) \\
(10 \%)\end{array}$ & $\begin{array}{c}0.010 \\
(0 \%) \\
(-20 \%) \\
\end{array}$ & $\begin{array}{c}0.375 \\
(0 \%) \\
(-47 \%)\end{array}$ & $\begin{array}{c}-0.197 \\
(0 \%) \\
(-36 \%)\end{array}$ & $\begin{array}{l}-12.639 \\
(267 \%) \\
(-60 \%)\end{array}$ & $\begin{array}{c}-4.621 \\
(1 \%) \\
(-41 \%)\end{array}$ & $\begin{array}{c}871.159 \\
(-62 \%)\end{array}$ & $\begin{array}{c}1 \\
(-89 \%) \\
\end{array}$ \\
\hline & 0 & $\begin{array}{c}-0.210 \\
(143 \%) \\
(98 \%) \\
\end{array}$ & $\begin{array}{c}-0.018 \\
(74 \%) \\
(-59 \%) \\
\end{array}$ & $\begin{array}{c}-0.523 \\
(40 \%) \\
(-11 \%) \\
\end{array}$ & $\begin{array}{c}-0.181 \\
(-8 \%) \\
(-39 \%) \\
\end{array}$ & $\begin{array}{r}-25.553 \\
(643 \%) \\
(-14 \%) \\
\end{array}$ & $\begin{array}{c}-4.624 \\
(1 \%) \\
(-40 \%) \\
\end{array}$ & $\begin{array}{c}1713.191 \\
(-17 \%) \\
\end{array}$ & $\begin{array}{c}2 \\
(-93 \%) \\
\end{array}$ \\
\hline \multirow{4}{*}{$\begin{array}{l}\text { Non-linear } \\
\text { Inelastic } \\
\text { (Case 1) }\end{array}$} & 15 & -0.122 & 0.020 & 0.408 & -0.313 & -3.261 & -4.387 & 0 & 0 \\
\hline & 5 & $\begin{array}{l}-0.143 \\
(17 \%) \\
(15 \%)\end{array}$ & $\begin{array}{c}0.020 \\
(0 \%) \\
(53 \%)\end{array}$ & $\begin{array}{l}-0.483 \\
(18 \%) \\
(-30 \%)\end{array}$ & $\begin{array}{c}-0.313 \\
(0 \%) \\
(0 \%)\end{array}$ & $\begin{array}{l}-10.777 \\
(230 \%) \\
(-64 \%)\end{array}$ & $\begin{array}{c}-4.388 \\
(0 \%) \\
(-45 \%)\end{array}$ & $\begin{array}{l}753.36 \\
(-64 \%)\end{array}$ & $\begin{array}{c}5 \\
(25 \%)\end{array}$ \\
\hline & 3 & $\begin{array}{l}-0.154 \\
(27 \%) \\
(40 \%) \\
\end{array}$ & $\begin{array}{c}0.020 \\
(0 \%) \\
(56 \%) \\
\end{array}$ & $\begin{array}{c}0.434 \\
(6 \%) \\
(-38 \%) \\
\end{array}$ & $\begin{array}{c}-0.314 \\
(0 \%) \\
(1 \%)\end{array}$ & $\begin{array}{l}-16.311 \\
(400 \%) \\
(-49 \%)\end{array}$ & $\begin{array}{c}-4.386 \\
(0 \%) \\
(-44 \%)\end{array}$ & $\begin{array}{l}1151.6 \\
(-50 \%) \\
\end{array}$ & $\begin{array}{c}7 \\
(-22 \%) \\
\end{array}$ \\
\hline & 0 & $\begin{array}{c}-0.223 \\
(83 \%) \\
(110 \%) \\
\end{array}$ & $\begin{array}{c}-0.033 \\
(63 \%) \\
(-24 \%) \\
\end{array}$ & $\begin{array}{l}-0.550 \\
(35 \%) \\
(-7 \%)\end{array}$ & $\begin{array}{c}-0.312 \\
(0 \%) \\
(5 \%) \\
\end{array}$ & $\begin{array}{l}-26.749 \\
(720 \%) \\
(-10 \%) \\
\end{array}$ & $\begin{array}{c}-4.374 \\
(0 \%) \\
(-43 \%) \\
\end{array}$ & $\begin{array}{c}1821.593 \\
(-12 \%)\end{array}$ & $\begin{array}{c}8 \\
(-72 \%) \\
\end{array}$ \\
\hline \multirow{4}{*}{$\begin{array}{l}\text { Non-linear } \\
\text { Inelastic } \\
\text { (Case 2) }\end{array}$} & 15 & -0.134 & 0.035 & 0.394 & -0.276 & -3.252 & -4.157 & 0 & 0 \\
\hline & 5 & $\begin{array}{c}-0.152 \\
(13 \%) \\
(22 \%) \\
\end{array}$ & $\begin{array}{c}0.035 \\
(0 \%) \\
(162 \%) \\
\end{array}$ & $\begin{array}{c}0.425 \\
(8 \%) \\
(-39 \%) \\
\end{array}$ & $\begin{array}{c}-0.275 \\
(0 \%) \\
(-12 \%) \\
\end{array}$ & $\begin{array}{l}-5.068 \\
(56 \%) \\
(-83 \%) \\
\end{array}$ & $\begin{array}{c}-4.157 \\
(0 \%) \\
(-48 \%) \\
\end{array}$ & $\begin{array}{l}336.41 \\
(-84 \%) \\
\end{array}$ & $\begin{array}{c}3 \\
(-25 \%) \\
\end{array}$ \\
\hline & 3 & $\begin{array}{l}-0.189 \\
(41 \%) \\
(71 \%) \\
\end{array}$ & $\begin{array}{c}102 \%) \\
0.035 \\
(0 \%) \\
(167 \%) \\
\end{array}$ & $\begin{array}{c}0.411 \\
(4 \%) \\
(-42 \%) \\
\end{array}$ & $\begin{array}{c}-0.276 \\
(0 \%) \\
(-11 \%) \\
\end{array}$ & $\begin{array}{c}-16.098 \\
(395 \%) \\
(-49 \%) \\
\end{array}$ & $\begin{array}{c}-4.157 \\
(0 \%) \\
(-47 \%) \\
\end{array}$ & $\begin{array}{l}1136.4 \\
(-51 \%) \\
\end{array}$ & $\begin{array}{c}3 \\
(-67 \%) \\
\end{array}$ \\
\hline & 0 & $\begin{array}{c}-0.239 \\
(79 \%) \\
(126 \%) \\
\end{array}$ & $\begin{array}{l}-0.041 \\
(17 \%) \\
(-8 \%) \\
\end{array}$ & $\begin{array}{c}-0.544 \\
(38 \%) \\
(-8 \%)\end{array}$ & $\begin{array}{c}-0.281 \\
(2 \%) \\
(-5 \%)\end{array}$ & $\begin{array}{l}-26.419 \\
(712 \%) \\
(-11 \%) \\
\end{array}$ & $\begin{array}{c}-4.149 \\
(0 \%) \\
(-46 \%) \\
\end{array}$ & $\begin{array}{c}1799.359 \\
(-13 \%)\end{array}$ & $\begin{array}{c}4 \\
(-86 \%) \\
\end{array}$ \\
\hline \multirow{4}{*}{$\begin{array}{l}\text { Non-linear } \\
\text { Inelastic } \\
\text { (Case 3) }\end{array}$} & 15 & -0.163 & 0.031 & 0.368 & -0.297 & -3.377 & -4.212 & 0 & 0 \\
\hline & 5 & $\begin{array}{c}-0.172 \\
(6 \%) \\
(39 \%)\end{array}$ & $\begin{array}{c}0.031 \\
(0 \%) \\
(132 \%)\end{array}$ & $\begin{array}{c}0.394 \\
(7 \%) \\
(-43 \%)\end{array}$ & $\begin{array}{c}-0.298 \\
(0 \%) \\
(-4 \%)\end{array}$ & $\begin{array}{l}-17.690 \\
(424 \%) \\
(-41 \%)\end{array}$ & $\begin{array}{c}-4.212 \\
(0 \%) \\
(-47 \%)\end{array}$ & $\begin{array}{l}1291.7 \\
(-38 \%)\end{array}$ & $\begin{array}{c}6 \\
(50 \%)\end{array}$ \\
\hline & 3 & $\begin{array}{c}-0.191 \\
(17 \%) \\
(73 \%) \\
\end{array}$ & $\begin{array}{c}0.030 \\
(-1 \%) \\
(133 \%) \\
\end{array}$ & $\begin{array}{c}-0.387 \\
(5 \%) \\
(-45 \%) \\
\end{array}$ & $\begin{array}{c}-0.299 \\
(1 \%) \\
(-3 \%)\end{array}$ & $\begin{array}{l}-17.513 \\
(419 \%) \\
(-45 \%)\end{array}$ & $\begin{array}{c}-4.212 \\
(0 \%) \\
(-46 \%)\end{array}$ & $\begin{array}{l}1266.6 \\
(-45 \%)\end{array}$ & $\begin{array}{c}5 \\
(-44 \%)\end{array}$ \\
\hline & 0 & $\begin{array}{c}-0.248 \\
(52 \%) \\
(134 \%) \\
\end{array}$ & $\begin{array}{l}-0.043 \\
(41 \%) \\
(-1 \%) \\
\end{array}$ & $\begin{array}{l}-0.555 \\
(51 \%) \\
(-6 \%)\end{array}$ & $\begin{array}{c}-0.300 \\
(1 \%) \\
(1 \%) \\
\end{array}$ & $\begin{array}{l}-26.759 \\
(692 \%) \\
(-10 \%) \\
\end{array}$ & $\begin{array}{c}-4.205 \\
(0 \%) \\
(-45 \%)\end{array}$ & $\begin{array}{c}1855.221 \\
(-10 \%)\end{array}$ & $\begin{array}{c}6 \\
(-79 \%) \\
\end{array}$ \\
\hline
\end{tabular}

a. The percentage below the values in blue color stands for the absolute percentage of increase or decrease regarding the corresponding case with no pounding. The percentage below the values in green color stands for the absolute percentage of increase or decrease regarding the corresponding linear elastic behavior case.

Table 3: Relevant results of the simulations carried out.

\section{CONCLUSIONS}

Earthquake-induced structural pounding between two SDOF structural systems was investigated. These systems can have elastic behavior or one of the four different types of hysteresis behavior considered with and without degradation features. 
Inelastic behavior was found to be very relevant when impacts between the SDOF structures occurred. Ultimately, elastic behavior overestimates the number and magnitude of impact forces and underestimates the displacements and accelerations that the structures might experience. These conclusions are particularly relevant for the case of the flexible structure.

It was found that the amplitude of the inelastic displacements, generally, exceeds the displacements in the elastic case, particularly, when the responses involve pounding and for hysteresis cases with degradation features. Among the hysteresis cases, the case with pinching presented the largest peak displacement and magnitude of the pounding forces for the scenario without space between the structures.

Permanent displacements were verified in the rebound direction, viz., in the flexible structure, caused by the action of the ground excitation and aggravated by the impact forces. These residual displacements increase as the gap between the adjacent structures decreases. Although there is no clear understanding of which hysteresis behavior the unrecoverable displacements are bigger since it also depends on the separation distance between the adjacent buildings. However, these tend to be slightly bigger for the case where stiffness and strength degradation are considered.

The hysteresis cycles revealed that pounding has very little or no effect on the right structure. The hysteresis loops when pounding is considered are almost coincident with the case of no pounding, showing very little deviation from it.

Regarding the acceleration responses, it is possible to verify the reduction of the number and magnitude of the acceleration spikes of both the left and right structures when the inelastic behavior is considered with respect to the elastic case.

This study only comprises SDOF structural systems under a specific ground motion. Further studies should include multiple DOFs, a three-dimensional spatial model, calibration of the hysteresis model with experimental data, and the consideration of several different ground motions to further validate the results presented in this study and add more relevant information to the problem of earthquake-induced structural building pounding.

\section{ACKNOWLEDGEMENTS}

This paper is within the scope of the first author's Ph.D. degree in progress, financially supported by the Portuguese Foundation for Science and Technology (FCT) through the PhD grant reference SFRH/BD/139570/2018 under the programme POCH (N2020 - P2020) and subsidized by the European Social Fund (FSE) and national funds from MCTES. This work was financially supported by: Base Funding - UIDB/04708/2020 of the CONSTRUCT - Instituto de I\&D em Estruturas e Construções - funded by national funds through the FCT/MCTES (PIDDAC).

\section{REFERENCES}

[1] M. V. Sivaselven and A. M. Reinhorn, "Hysteretic models for deteriorating inelastic structures," Journal of Engineering Mechanics, vol. 126, no. 6, pp. 633-640, 2000.

[2] Bouc, R. "Forced vibration of mechanical systems with hysteresis". Proceedings of the Fourth Conference on Non-linear oscillation. Prague, Czechoslovakia. 1967.

[3] Y.-K. Wen, "Method for Random Vibration of Hysteretic Systems," Journal of the Engineering Mechanics Division, ASCE, vol. 102, no. 2, pp. 249-263, 1976. 
[4] Y.-K. Wen, "Equivalent Linearization for Hysteretic System under Random Excitation," Journal of Applied Mechanics, ASME, vol. 47, no. 1, pp. 150-154, 1980.

[5] S. A. Mousavi, S. M. Zahrai, and M. Saatcioglu, "Toward buckling free tension-only braces using slack free connections," Journal of Constructional Steel Research, vol. 115, pp. 329-345, 2015.

[6] Y. J. Park, A. M. Reinhorn and S. K. Kunnath, "IDARC: Inelastic Damage Analysis of Reinforced Concrete Frame - Shear-Wall Structures," Technical Report NCEER-870008, National Center for Earthquake Engineering Research, University at Buffalo, State University of New York, Buffalo, New York, USA, 1987.

[7] S. K. Kunnath, A. M. Reinhorn and Y. J. Park, "Analytical modeling of inelastic seismic response of RC structures," Journal of Structural Engineering, ASCE, vol. 116, no. 4, pp. 996-1017, 1990.

[8] Federal Emergency Management Agency (FEMA) P440A, Effects of Strength and Stiffness Degradation on Seismic Response, Redwood City, California: Applied Technology Council, 2009.

[9] S. Otani, Nonlinear Earthquake Response Analysis of Reinforced Concrete Buildings (Lecture Notes), Tokyo, Japan: Department of Architecture, Graduate School of Engineering, University of Tokyo, 2002.

[10] R. Jankowski and S. Mahmoud, Earthquake-Induced Structural Pounding, Switzerland: Springer, 2015.

[11] Goldsmith, W. Impact: The Theory and Physical Behaviour of Colliding Solids. Edward Arnold (Publishers) LTD: London. 1960.

[12] M. Mahmoud, K. Choong, and R. Jankowski, "Seismic pounding between adjacent buildings: Identification of parameters, soil interaction issues and mitigation measures," Soil Dynamics and Earthquake Engineering, vol. 121, pp. 135-150, 2019.

[13] K. Johnson, "Contact Mechanics," Cambridge university press, 1987.

[14] H. Hertz, "Über die Berührung fester elastischer Körper (On the contact of elastic solids)," J. für die Reine und Angewandte Mathematik, vol. 29, pp. 156-171, 1881. (in German)

[15] J. Wolf and P. Skrikerud, "Mutual pounding of adjacent structures during earthquakes," Nuclear Engineering and Design, vol. 57, pp. 253-275, 1980.

[16] S. Anagnostopoulos, "Pounding of buildings in series during earthquakes," Earthquake Engineering and Structural Dynamics, vol. 16, pp. 443-456, 1988.

[17] S. Anagnostopoulos, "Equivalent viscous damping for modeling inelastic impacts in earthquake pounding problems," Earthquake Engineering and Structural Dynamics, vol. 33, pp. 897-902, 2004.

[18] P. Komodromos, P. Polycarpou, L. Papaloizo, and M. Phocas, "Response of seismically isolated buildings considering poundings," Earthquake Engineering and Structural Dynamics, vol. 36, pp. 1605-1622, 2007.

[19] R. Valles and A. Reinhorn, "Evaluation, prevention and mitigation of pounding effects in building structures," Technical Report NCEER-97-0001, National Center for Earthquake Engineering Research, State University of New York, Buffalo, USA, 1997. 
[20] S. Mahmoud, "Modified linear viscoelastic model for elimination of the tension force in the linear viscoelastic," in The Fourteenth World Conference on Earthquake Engineering, October 12-17, 2008, Beijing, China, 2008.

[21] K. Ye, L. Li and H. Zhu, "A modified Kelvin impact model for pounding simulation of base-isolated building with adjacent structures," Earthquake Engineering and Engineering Vibration, vol. 8, pp. 433-446, 2009.

[22] D. Pant, A. Wijeyewickrema and T. Ohmachi, "Three dimensional nonlinear analysis of seismic pounding between multi-story reinforced concrete buildings," in Proceedings of the Seventh International Conference on Urban Earthquake Engineering (7CUEE) and Fifth International Conference on Earthquake Engineering (5ICEE), Vol II: 1829-1840, 2010.

[23] D. Pant, A. Wijeyewickrema and T. Ohmachi, "Seismic Pounding between Reinforced Concrete Buildings: A Study using two recently proposed Contact Element Models," in Proceeding of the 14th European Conference on Earthquake Engineering, European Conference on Earthquake Engineering, Republic of Macedonia, 2010.

[24] S. Mahmoud and R. Jankowski, "Modified linear viscoelastic model of earthquakeinduced structural pounding," Iranian Journal of Science and Technology, vol. 35, no. C1, pp. 51-62, 2011.

[25] H. Lankarani and P. Nikravesh, "A Contact Force Model With Hysteresis Damping for Impact Analysis of Multibody Systems," Journal of Mechanical Design, vol. 112, pp. 369-376, 1990.

[26] H. Lankarani and P. Nikravesh, "Continuous Contact Force Models for Impact Analysis in Multibody Systems," Nonlinear Dynamics, vol. 5, pp. 193-207, 1994.

[27] K. Hunt and F. Crossley, "Coefficient of restitution interpreted as damping in vibroimpact," Journal of Applied Mechanics, American Society of Mechanical Engineers, vol. 42, pp. 440-445, 1975.

[28] S. Muthukumar, "A contact element approach with hysteresis damping for the analysis and design of pounding in bridges," Ph.D. Thesis, Georgia Institute of Technology, Georgia, EUA, 2003.

[29] S. Muthukumar and R. DesRoches, "A Hertz contact model with non-linear damping for pounding simulation," Earthquake Engineering and Structural Dynamics, vol. 35, pp. 811-829, 2006.

[30] R. Jankowski, "Non-linear viscoelastic modelling of earthquake-induced structural pounding," Earthquake Engineering and Structural Dynamics, vol. 34, pp. 595-611, 2005 .

[31] R. Jankowski, "Analytical expression between the impact damping ratio and the coefficient of restitution in the non-linear viscoelastic model of structural pounding," Earthquake Engineering and Structural Dynamics, vol. 35, pp. 517-524, 2006.

[32] K. Ye, L. Li and H. Zhu, "A note on the Hertz contact model with nonlinear damping for pounding simulation," Earthquake Engineering and Structural Dynamics, vol. 38, pp. 1135-1142, 2009. 
[33] H. Naderpour, R. Barros, and S. Khatami, "A new model for calculating impact force and energy dissipation based on the CR-factor and impact velocity," Scientia Iranica A, vol. 22, pp. 59-68, 2015.

[34] H. Naderpour, R. Barros, R. Khatami, and R. Jankowski, "Numerical Study on Pounding between Two Adjacent Buildings under Earthquake Excitation," Hindawi Publishing Corporation: Shock and Vibration, vol. 2016, 2016.

[35] S. Khatami, H. Naderpour, R. C. Barros, A. Jakubczyk-Gałczynska and R. Jankowski, "Effective Formula for Impact Damping Ratio for Simulation of Earthquake-induced Structural Pounding," Geosciences, MDPI, vol. 9, no. 8: 347, 2019.

[36] F. Bamer, "A Hertz-pounding formulation with a nonlinear damping and a dry friction element," Acta Mechanica, vol. 229, pp. 4485-4494, 2018.

[37] F. Bamer and B. Markert, "A nonlinear visco-elastoplastic model for structural pounding," Earthquake Engineering and Structural Dynamics, vol. 47(12), pp. 2490-2495, 2018.

[38] F. Bamer, N. Strubel, J. Shi and B. Markert, "A visco-elastoplastic pounding damage formulation,” Engineering Structures, vol. 197, 2019.

[39] R. Jankowski, "Experimental study on earthquake-induced pounding between structural elements made of different building materials," Earthquake Engineering and Structural Dynamics, vol. 39, pp. 349-354, 2010.

[40] J. van Mier, A. F. Pruijssers, H. Reinhardt and T. Monnier, "Load-Time Response of Colliding Concrete Bodies," Journal of Structural Engineering, Vols. 117, No. 2, no. 25544, pp. 354-374, 1991.

[41] K. Chau, X. Wei, X. Guo and C. Shen, "Experimental and theoretical simulations of seismic poundings between two adjacent structures," Earthquake Engineering and Structural Dynamics, vol. 32, pp. 537-554, 2003.

[42] M. Goland, P. Wickersham, and M. Dengler, "Propagation of elastic impact in beams in bending," Journal of Applied Mechanics, vol. 22, pp. 1-7, 1955.

[43] P. Zhu, M. Abe, and Y. Fujino, "Modelling three-dimensional non-linear seismic performance of elevated bridges with emphasis on pounding of girders," Earthquake Engineering and Structural Dynamics, vol. 31, pp. 1891-1913, 2002.

[44] P. Polycarpou, L. Papaloizou, P. Komodromos, “An efficient methodology for simulating earthquake-induced 3D pounding of buildings", Earthquake Engineering and Structural Dynamics, vol. 43, pp. 985-1003, 2014.

[45] Pacific Earthquake Engineering Research Center (PEER) strong ground motion database, [Online]. Available: https://peer.berkeley.edu/peer-strong-ground-motiondatabases.

[46] MATLAB 2014a., Natick, Massachusetts, USA: MathWorks, Inc., 2014. 